This document is the accepted manuscript version of the following article:

Ghourchian, S., Wyrzykowski, M., Plamondon, M., \& Lura, P. (2019). On the mechanism of plastic shrinkage cracking in fresh cementitious materials. Cement and Concrete Research, 115,

251-263. https://doi.org/10.1016/j.cemconres.2018.10.015

This manuscript version is made available under the CC-BY-NC-ND 4.0

license http://creativecommons.org/1icenses/by-nc-nd/4.0/

Accepted version. Paper published as: Ghourchian et al., On the mechanism of plastic shrinkage cracking in fresh cementitious materials. Cem Concr Res (2019) 115: 251-263

https://doi.org/10.1016/i.cemconres.2018.10.015

\title{
On the mechanism of plastic shrinkage cracking in
}

\section{fresh cementitious materials}

\author{
Sadegh Ghourchian ${ }^{1,2, *}$, Mateusz Wyrzykowski ${ }^{1}$, Mathieu Plamondon ${ }^{1}$, Pietro Lura ${ }^{1,2}$ \\ ${ }^{1}$ Empa, Swiss Federal Laboratories for Materials Science and Technology, Dübendorf, \\ Switzerland \\ ${ }^{2}$ Institute for Building Materials (IfB), ETH Zurich, Switzerland \\ ${ }^{*}$ Corresponding author: sadegh.ghourchian@empa.ch
}

\begin{abstract}
In this study, a continuum poromechanics approach is presented to model the plastic shrinkage cracking of fresh cementitious materials. The boundary conditions are according to the modified ASTM C1579-13 standard for mortars. The restrained deformations are linked to the restraint stresses according to the Cauchy-Navier equations of elasticity, assuming an incremental stressstrain relationship. The Bresler-Pister and Rankine failure criteria are utilized to model failure. The material parameters are adapted according to the Drucker-Prager and Griffith criteria. The crack initiation and propagation is verified experimentally by X-ray radiography. Eventually, the cracking mechanism is discussed and a safe capillary pressure limit is proposed. It is found that capillary pressure stiffening occurring before air entry, when deformations take place in the saturated state, is the predominant cause of plastic shrinkage cracking in the drying state.
\end{abstract}

Keywords: Fresh Concrete (A); Crack Detection (B); Shrinkage (C); Mechanical Properties (C); Finite Element Analysis (C) 
Accepted version. Paper published as: Ghourchian et al., On the mechanism of plastic shrinkage cracking in fresh cementitious materials. Cem Concr Res (2019) 115: 251-263

https://doi.org/10.1016/j.cemconres.2018.10.015

\section{Nomenclature}

$b[\mathrm{~m} / \mathrm{s}]$ : bleeding rate

$B$ [Pa]: bulk modulus

$B_{0}[\mathrm{~Pa}]$ : initial bulk modulus

$B_{b}[\mathrm{~Pa}]$ : bulk modulus in bleeding state

$B_{e}[\mathrm{~Pa}]$ : bulk modulus in drying state

$c[\mathrm{~Pa}]$ : cohesion in Mohr-Coulomb model

$C[\mathrm{~Pa}]$ : cohesion in Drucker-Prager model

$e\left[\mathrm{~kg} / \mathrm{m}^{2} / \mathrm{h}\right]$ : evaporation rate

$\vec{g}\left[\mathrm{~m} / \mathrm{s}^{2}\right]$ : gravity acceleration vector

$h[\mathrm{~m}]$ : height of sample

$\boldsymbol{I}[-]$ : unit tensor

$I_{1}[\mathrm{~Pa}]$ : first invariant of the effective stress tensor

$J_{2}\left[\mathrm{~Pa}^{2}\right]$ : second invariant of the effective deviatoric stress tensor

$\boldsymbol{n}[\mathrm{m}]$ : normal direction vector of the surface

$p_{c}[\mathrm{~Pa}]$ : capillary pressure

$p_{c \text {-safe }}[\mathrm{Pa}]$ : safe capillary pressure

$p_{\text {pel-c }}[\mathrm{Pa}]:$ compressive pseudo-elastic limit

$p_{\text {pel- }}[\mathrm{Pa}]$ : tensile pseudo-elastic limit

$S_{w}[-]$ : saturation degree

$t$ [min]: time from mixing start

$t_{\text {cass }}[\mathrm{min}]$ : casting time from mixing start

$t^{*}[\mathrm{~min}]$ : hydration characteristic time

$z[\mathrm{~m}]$ : elevation from bottom of sample

$\varepsilon_{x x}=\varepsilon_{y y}[-]:$ horizontal strains

$\varepsilon_{z z}[-]$ : vertical strain

$\varepsilon_{v o l}[-]$ : volumetric strain

$\lambda$ [degree]: angle of stress path

$v[-]$ : Poisson's ratio

$\xi[-]$ : parameter defining the maximum effect of capillary pressure on fresh concrete stiffness

$\rho_{C:}\left[\mathrm{kg} / \mathrm{m}^{3}\right]:$ concrete density

$\rho_{f}\left[\mathrm{~kg} / \mathrm{m}^{3}\right]$ : density of the pore fluid

$\rho_{w}\left[\mathrm{~kg} / \mathrm{m}^{3}\right]$ : density of water

$\sigma_{s w}[\mathrm{~Pa}]$ : self-weight stress

$\sigma_{e x}[\mathrm{~Pa}]:$ external load (stress)

$\sigma_{\text {eff }}[\mathrm{Pa}]:$ effective stress

$\sigma_{r}[\mathrm{~Pa}]:$ effective restraint stress

$\sigma_{y c}[\mathrm{~Pa}]$ : uniaxial compressive strength

$\sigma_{y t}[\mathrm{~Pa}]$ : uniaxial tensile strength

$\varphi$ [degree]: angle of internal friction in Mohr-Coulomb model

$\phi$ [degree]: angle of internal friction in Drucker-Prager model

$\psi_{p}[\mathrm{~Pa}]$ : pore fluid's pressure potential

$\omega[1 / \mathrm{Pa}]$ : parameter controlling the rate of increase of fresh concrete stiffness with capillary pressure 
Accepted version. Paper published as: Ghourchian et al., On the mechanism of plastic shrinkage cracking in fresh cementitious materials. Cem Concr Res (2019) 115: 251-263

https://doi.org/10.1016/j.cemconres.2018.10.015

\section{Introduction}

Early-age cracking, which often occurs as a consequence of restrained deformations, including plastic shrinkage [1-3], may compromise the durability and reduce the service life of concrete structures. Plastic shrinkage is the volumetric deformation of fresh concrete before final set [4-6]. Plastic shrinkage may lead to localized, macroscopic cracking in the case of concrete elements with differential depth or in the presence of restraints such as reinforcing bars, studs or dents on the substrate base and friction between the substrate base and the layer of fresh concrete [7-9]. Failure occurs due to the local magnitude of the deviatoric stresses exceeding the failure limit of the fresh concrete. Plastic shrinkage, both in bleeding [6,10] and drying [11-13] states, has been estimated to be the source of about roughly $80 \%$ of early-age cracks in concrete structures [14]. The large economic impact of plastic shrinkage cracking motivates the necessity of a thorough understanding of its mechanisms, which is a prerequisite for developing and prescribing suitable mitigation methods. Nevertheless, the majority of studies about plastic shrinkage cracking is purely experimental (see Table 1), and very few analytical and numerical models are available. Kwak et al. [14] modeled the self-weight consolidation of saturated fresh mortars restrained by rebars using the three dimensional small-strain consolidation theory for soil. However, their approach neglects the non-linearity due to the evolution in time of the stiffness. The evolution of the elastic properties in fresh concrete in the drying state is caused both by cement hydration and by capillary-pressure stiffening [15]. A truly robust and accurate model needs to consider an incremental stress-strain relationship for fresh cementitious materials, as explained in this study and in [15]. For the drying state, Morris and Dux modeled plastic shrinkage cracking by approximating the stress intensity factor and its critical value, however without presenting an experimental validation [1]. Furthermore, Slowik et al. [16,17] modeled the plastic shrinkage cracking of an inert material without cement hydration by simulating the interaction of the forces acting on the solid particles at the microscale. However, in order to develop solutions to mitigate cracking, plastic shrinkage cracking needs to be modeled at the macroscale, by considering the development of stresses due to restrained deformations.

Various experimental methods for studying plastic shrinkage cracking of concrete and mitigation methods have been developed, as summarized in Table 1. Virtually all methods rely on the measurement of the features of the final $\operatorname{crack}(\mathrm{s})$ apparent on the concrete surface; this 
Accepted version. Paper published as: Ghourchian et al., On the mechanism of plastic shrinkage cracking in fresh cementitious materials. Cem Concr Res (2019) 115: 251-263

https://doi.org/10.1016/j.cemconres.2018.10.015

measurement is thus the final result of crack initiation (i.e. failure, which may happen far from the surface) and propagation to the surface. Consequently, if a crack does not propagate to the surface, no meaningful results can be obtained in those methods. Apart from the latter, according to classical engineering failure criteria [18], the damage is defined (and the measures are taken to avoid it) in terms of the crack initiation, when the stress goes beyond the strength envelope, rather than by considering further crack propagation. The fib Model Code for Concrete Structures 2010 [19], classifies any local damages (which do not affect structural safety but may influence the efficiency of structural or non-structural components) as the "serviceability limit state criteria". Local damage (i.e. crack initiation) needs to be avoided, since dormant cracks can propagate further when the required conditions are satisfied, due to the stress concentration existing at the tip of the crack [20]. The latter criteria are in line with a number of experimental and analytical studies [21-25] showing the effect of localized cracking and distributed microcracking on increasing fluid and ion transport in concrete, ultimately leading to decreased serviceability. Therefore, crack initiation, which can be considered as local damage influencing the durability of concrete structures, should be chosen as a criterion for comparing the performance of different concrete mixtures, rather than the characteristics of the cracks that appear on the concrete surface. Consequently, experimental methods which can detect the damage (crack) before propagation are desirable. In [26], a mold with two transparent walls allowed detecting of the crack initiation. However, a drawback of this method is that the observed behavior can be affected by the wall effect. In fact, according to the ASTM C1579-13 standard [27], the cracks observed within $25 \mathrm{~mm}$ from the walls should be neglected in the measurements of the crack width distribution.

Based on the arguments discussed above, it is evident that an appropriate experimental set-up and an analytical model are necessary to detect the plastic shrinkage damage initiation; this is the main objective of the present study. For the experimental detection of crack initiation, X-ray radiography was carried out on a sample cast in a modified ASTM C1579-13 [27] mold for mortars. X-ray radiography allowed to detect the crack before its propagation to the surface. This is a clear advantage compared to a standard method where only crack opening at the surface can be assessed. For the numerical procedure, a previously-developed model for simulating free plastic shrinkage explained in [15] was used as input to the structural mechanics module in COMSOL Multiphysics ${ }^{\circledR}$. 
Accepted version. Paper published as: Ghourchian et al., On the mechanism of plastic shrinkage cracking in fresh cementitious materials. Cem Concr Res (2019) 115: 251-263

https://doi.org/10.1016/j.cemconres.2018.10.015

Tensile strength is a key material property in studies related to concrete's failure, and particularly plastic shrinkage cracking $[1,13,28,29]$. Even though tensile strength is related to cohesion commonly measured in soils, the experimental measurements are very challenging for fresh concrete, due to a low strength at very early ages. The drawbacks of available methods are extensively discussed in [30]. Although many efforts have been made to measure the strength properties of fresh concrete, the outcome is limited, and might be affected by a series of artifacts [30]. In this study, an attempt is made to present an indirect method for predicting the cohesion and tensile strength of fresh cementitious materials, according to the available multiaxial failure envelopes for porous materials, i.e. soil and concrete. In a multiaxial failure envelope, all strength properties are related according to the equation of the failure limit. In other words, by the measurement of a strength property, e.g. the pseudo-elastic limit, one can estimate the tensile strength. The pseudo-elastic compressive isotropic stress limit [31], which separates the elastic and plastic zones in the mechanical response of fresh cementitious materials, was determined by utilizing the experimentally-validated approach by Casagrande [32] on the modeled stress-strain curves, according to the isotropic, stress-dependent bulk modulus evolution determined in [15].

The Bresler-Pister failure criterion [18,33,34] was applied for predicting crack initiation. This model was chosen due to the fact that it covers the failure zones of multiaxial stresses, from pure hydrostatic failure (which can happen for porous geomaterials, referred to as cap failure) to shear and tensile failures. Thanks to this approach, it was possible to relate the pseudo-elastic limit (which relates to pure hydrostatic failure), to the failure envelope in shear and tension, to study plastic shrinkage cracking. Additionally, after modeling the uniaxial tensile strength, the Rankine (maximum tensile principal stress) failure criterion for brittle materials $[18,35]$ was also utilized to study the failure initiation. The material parameters for the cohesion strength used in the BreslerPister criterion were adapted according to the Drucker-Prager model at pure shear failure $[33,36,37]$ and the Griffith's model for tensile failure as explained in Appendix A. Relating the Bresler-Pisler model to the latter two models allowed to utilize an already-available estimation of the internal friction angle of fresh mortar and to relate the pseudo-elastic stress limit to the tensile strength, by explaining the evolution of cohesion as a linear function of the evolution of the pseudo-elastic limit. Eventually, the model was validated by comparing the predicted crack 
Accepted version. Paper published as: Ghourchian et al., On the mechanism of plastic shrinkage cracking in fresh cementitious materials. Cem Concr Res (2019) 115: 251-263 https://doi.org/10.1016/j.cemconres.2018.10.015

initiation with X-ray radiography data. A safe limit was proposed for the development of capillary pressure as a benchmark for avoiding plastic shrinkage cracking in the drying state.

Table 1. Methods used for quantifying plastic shrinkage damage

\begin{tabular}{|c|c|c|c|}
\hline Item & Authors & Test method & Measured quantity \\
\hline $\mathrm{a}$ & $\begin{array}{l}\text { Lura et al. [38], Leemann et al. [39], Fontana et } \\
\text { al. [40], Norfleet [41], Sivakumar [42], Rahmani } \\
\text { et al. [43], Qi et al. [44], Ranjbar [45], Combrinck } \\
\text { and Boshof [46], Hossain et al. [47,48], } \\
\text { Henkensiefken et al. [49], Yang et al.[50], } \\
\text { Soroushian et al. [51] }\end{array}$ & $\begin{array}{c}\text { ASTM C1579 [27]: Cubic mold with } \\
\text { three lateral stress risers (triangular } \\
\text { section) }\end{array}$ & $\begin{array}{c}\text { Crack length, width, } \\
\text { area }\end{array}$ \\
\hline $\mathrm{b}$ & $\begin{array}{c}\text { Berke and Dallaire[52], } \\
\text { Sivakumar and Santhanam[29,53], Shao and } \\
\text { Mirmiran [54], Mora-Ruacho et al. [55], Boshoff } \\
\text { and Combrinck [56] }\end{array}$ & $\begin{array}{l}\text { Modified ASTM C1579 with extra bolt } \\
\text { and nut or arrangements at sides or } \\
\text { reinforcing bars in both directions to } \\
\text { increase the potential of cracking }\end{array}$ & $\begin{array}{l}\text { Crack length, width, } \\
\text { area }\end{array}$ \\
\hline $\mathrm{c}$ & $\begin{array}{l}\text { Fontana et al. [40], Löfgren et al. [57], Hwang et } \\
\text { al. [58], Branch et al.[59], } \\
\text { Esping [60], Sayahi et al. [61], Toledo Filho and } \\
\text { Sanjuan [62], Balaguru and Shah [63] }\end{array}$ & $\begin{array}{c}\text { ÖVBB [40], and NORDTEST NT } \\
\text { BUILD 433[64]: Ring shape mold with } \\
\text { perimeter restraints by expanded metal } \\
\text { lath-Ring shape mold, and with rebars } \\
\text { positioned at the mid-height of the mold } \\
{[62]}\end{array}$ & Crack area \\
\hline $\mathrm{d}$ & Liu [65] & Dumbbell shape mold & Crack width \\
\hline $\mathrm{e}$ & $\begin{array}{l}\text { Fontana et al. [40], Lin et al. [66-68], Shen et al. } \\
\text { [69], Ruiz-Ripoll et al. [70] }\end{array}$ & $\begin{array}{l}\text { DIBt method [40], Shallow cubic mold } \\
\text { with threaded steel rebars to provide the } \\
\text { boundary restraint and differential } \\
\text { depth. }\end{array}$ & $\begin{array}{l}\text { Crack area, width, } \\
\text { and length }\end{array}$ \\
\hline $\mathrm{f}$ & $\begin{array}{l}\text { Banthia et al. [71], Banthia and Gupta [7,72,73], } \\
\text { Ghoddousi and Javid [74], Malathy et al. [75], } \\
\text { Senthilkumar and Natesan [76], Nabil et al. [77] }\end{array}$ & $\begin{array}{l}\text { Concrete was placed on a substrate base } \\
\text { with several protuberances, exposed } \\
\text { coarse aggregates or dents on the } \\
\text { surface working as stress risers }\end{array}$ & $\begin{array}{l}\text { Crack area, width, } \\
\text { length }\end{array}$ \\
\hline $\mathrm{g}$ & Li and Qian [78] & $\begin{array}{l}\text { GB/T 50082-2009[79]: Cubic mold } \\
\text { with seven composite shape lateral } \\
\text { stress risers }\end{array}$ & Crack width, area \\
\hline $\mathrm{h}$ & $\begin{array}{c}\text { Kraai[80], Shaeles et al.[81], Soroushian et } \\
\text { al.[51], Eren et al.[82], Ramakrishnan et al. [83], } \\
\text { Gunasekaran[84], Pelisser et al. [85], Medina et } \\
\text { al. [86] }\end{array}$ & $\begin{array}{l}\text { Shallow flat cubic mold with perimeter } \\
\text { restraints by L-shaped hardware cloth } \\
\text { or expanded metal lath }\end{array}$ & $\begin{array}{l}\text { Crack length, width, } \\
\text { area }\end{array}$ \\
\hline $\mathrm{i}$ & Hosoda [87] & $\begin{array}{c}\text { Shallow flat cubic mold with eight } \\
\text { lateral rebar stress risers welded to } \\
\text { bottom of the mold }\end{array}$ & Crack area \\
\hline $\mathrm{j}$ & Alhozaimi and Al-Negheimish [88] & $\begin{array}{c}\text { Slabs were reinforced in both directions } \\
\text { with four steel bars spaced at the } \\
\text { middle height }\end{array}$ & Crack width, area \\
\hline
\end{tabular}

\section{Model derivation}

In [89] and [15], the bulk modulus of a fresh plastic concrete $\left(B_{e}[\mathrm{~Pa}]\right)$ was found to be non-linearly dependent upon: 1- cement hydration, as explained in [89], and 2- the applied isotropic compressive stress [90] (i.e. capillary pressure), after the solid percolation threshold, according to the relationship proposed by Alonso et al. [91]: 
Accepted version. Paper published as: Ghourchian et al., On the mechanism of plastic shrinkage cracking in fresh cementitious materials. Cem Concr Res (2019) 115: 251-263

https://doi.org/10.1016/j.cemconres.2018.10.015

$$
B_{e}=B_{b}\left[(1-\xi) \exp \left(-\omega \sigma_{e f f}\right)+\xi\right]
$$

where $B_{b}[\mathrm{~Pa}]$ is the bulk modulus in absence of capillary pressure (in bleeding conditions), dependent only upon hydration of cement. In eq. (1), $\xi[-]$ is a parameter defining the maximum effect of the capillary pressure on the fresh concrete stiffness and $\omega[1 / \mathrm{Pa}]$ is a parameter controlling the rate of increase of fresh concrete stiffness with the capillary pressure. In this study, the parameters of eq. (1) were obtained by fitting the incremental stress-strain relationship:

$$
d \varepsilon_{v o l}=d \sigma_{e f f} / B_{e}
$$

to the experimentally-obtained incremental effective stress, $d \sigma_{\text {eff }}[\mathrm{Pa}]$, vs. volumetric strain, $d \varepsilon_{v o l}[-$ ]. The experimental data comes from the plastic shrinkage experiment performed in [15] for the same mortars as tested in this study.

Now let us consider the quasi instantaneous (compared to the kinetics of hydration) stress-strain relationship at a given (fixed) time instant, i.e. for a constant $B b$. It can be readily seen that, even when excluding the evolution of hydration in the $B_{b}$ term in eq. (1), the stress-strain relationship is still nonlinear due to the dependence of stiffness upon stress. Thus, an incremental form eq. (2) is used also at a fixed time. Combining eq. (1) and (2) one obtains:

$$
d \varepsilon_{v o l}=\frac{d \sigma_{e f f}}{B_{b}\left[(1-\xi) \exp \left(-\omega \sigma_{e f f}\right)+\xi\right]}
$$

Integration of both sides of eq. (3), assuming the initial values of stress and strain equal to zero, leads to the stress-strain relationship at a given time instant:

$$
\varepsilon_{v o l}=\frac{\ln \left(\xi\left[\exp \left(\omega \sigma_{e f f}\right)-1\right]+1\right)}{B_{b} \xi \omega}
$$

The stress-strain relationship described with eq. (4) is presented in Fig. 1 for two exemplary degrees of hydration (two different time instants). The stress-strain curves are used for estimating the compressive pseudo-elastic limit ( $\left.p_{\text {pel-c }}[\mathrm{Pa}]\right)[31,92]$ at time $t$, which separates the elastic and plastic domains for the mechanical response of fresh cementitious materials, according to Casagrande's graphical method [32]. The method is based on finding the pseudo-elastic limit as 
Accepted version. Paper published as: Ghourchian et al., On the mechanism of plastic shrinkage cracking in fresh cementitious materials. Cem Concr Res (2019) 115: 251-263 https://doi.org/10.1016/j.cemconres.2018.10.015

corresponding to the intersection between the slope of the stress-strain curve in the plastic domain (referred to as the virgin compression line in [32]) and the bisector of the tangent at maximum curvature with the vertical line. As presented in Fig. 1, ppel-c becomes higher with increasing hydration degree of cement. In fact, the pseudo-elastic limit can be referred to as the strength of fresh concrete for the hydrostatic stress (i.e. isotropic stress), which increases with hydration.

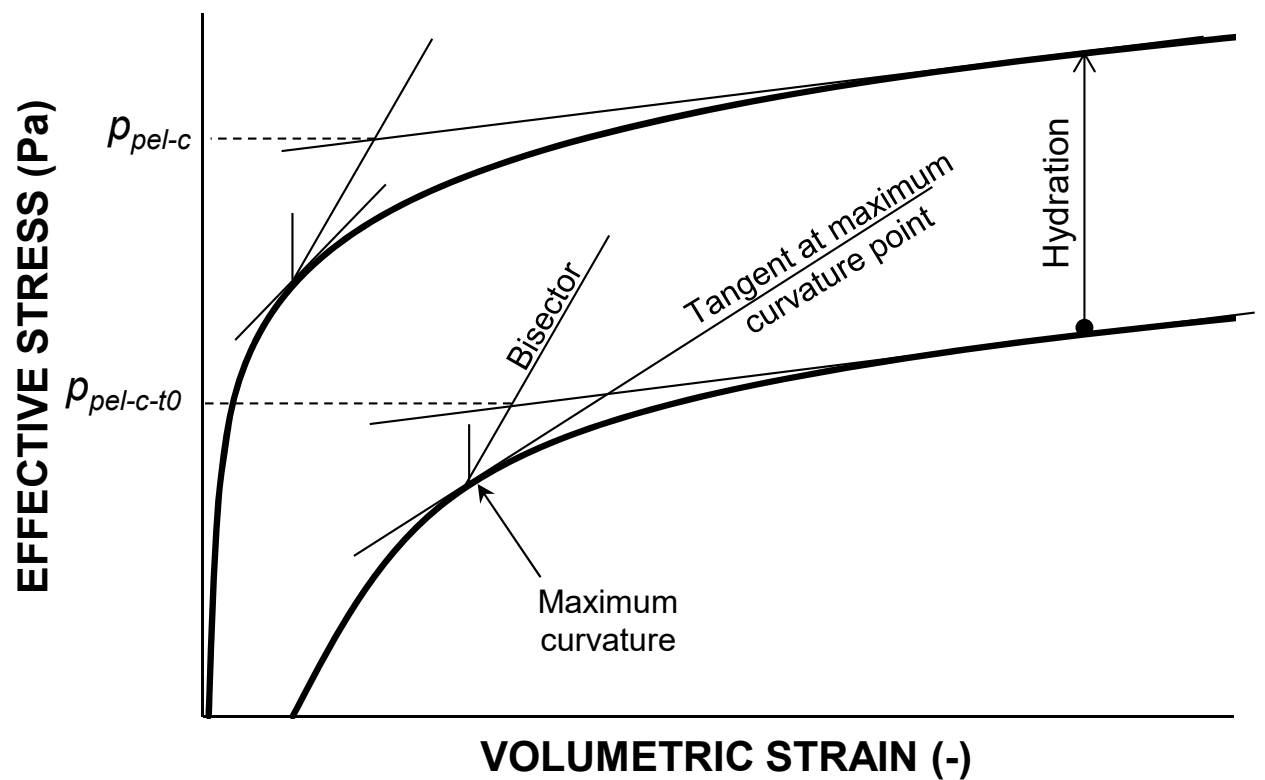

Fig. 1. Schematic evolution of isotropic effective stress vs. volumetric strain curves in fresh cementitious material. The compressive pseudo-elastic stress limit $\left(p_{\text {pel-c }}\right)$, which increases with hydration, was determined according to Casagrande's graphical method [32,92]. The vertical axis is in the logarithmic scale. The subscript t0 denotes the initial value at the time of mixing.

\section{Analytical and numerical methods}

\subsection{Effective stress tensor}

According to Terzaghi [93], the effective stress is the part of the total stress in a porous body that results in measurable effects (deformations or increase of shearing resistance) and is expressed as:

$$
\boldsymbol{\sigma} e f f=\boldsymbol{\sigma}-\psi_{p} \mathbf{I}
$$

where $\mathbf{I}$ is a $3 \times 3$ identity matrix, and $\psi_{p}[\mathrm{~Pa}]$ is the pore water pressure. $\boldsymbol{\sigma}[\mathrm{Pa}]$ is the total stress tensor. The latter (in absence of external loads) is only due to self-weight, which in a nonconsolidated fresh concrete (before percolation of solids) can only be transferred through the pore 
Accepted version. Paper published as: Ghourchian et al., On the mechanism of plastic shrinkage cracking in fresh cementitious materials. Cem Concr Res (2019) 115: 251-263

https://doi.org/10.1016/j.cemconres.2018.10.015

fluid and hence is an isotropic stress equal to $\rho_{c} g(h-z) \mathbf{I}$ where $h[\mathrm{~m}]$ is the total height of concrete layer, $\rho_{c}\left[\mathrm{~kg} / \mathrm{m}^{3}\right]$ is the concrete density, $g\left[\mathrm{~m} / \mathrm{s}^{2}\right]$ is the gravity acceleration, and $z[\mathrm{~m}]$ is the elevation from the sample's bottom (see [89]). Since in the model presented here an incremental form of the equations is used, the changes of effective stress are only due to changes of pore water pressure, the latter being initially due to consolidation, and after onset of drying due to capillary pressure (see [15]). Hence, the stress tensor is always isotropic for the plastic shrinkage problem. In eq. (5), the pore pressure is assumed to be exerted by the pore water only after desaturation. This neglects the contribution of the gaseous phase, based on the fact that the saturation degree is always close to $1(>0.9995)$ during plastic shrinkage (see [15]). In this study, the compressive stress and the shrinkage are assumed positive. The pore water pressure is assumed positive for compression of the fluid (hence, capillary pressure corresponds to negative pore pressure, i.e. suction). The pore pressure and the resulting effective stress development were modeled in [15] utilizing the generalized consolidation equation. The free horizontal and vertical shrinkage were calculated by the effective isotropic stress development model as explained in [15] and were utilized here in an incremental form as input for the model of restraint stress.

The equations of equilibrium [94] for an increment of the restraint stress $d \boldsymbol{\sigma}_{r}$ reads:

$$
\nabla \cdot\left(d \boldsymbol{\sigma}_{r}\right)=0
$$

Assuming $x$ (out-of-plane) and $y$ (in-plane) as horizontal directions and $z$ the vertical direction, for a plane strain problem in the yz plane, and considering the symmetry of the stress tensor, the incremental stress-strain relationship for an isotropic material under plane strain condition is [95]:

$$
\left[\begin{array}{l}
d \sigma_{y y} \\
d \sigma_{z z} \\
d \sigma_{y z}
\end{array}\right]_{r}=\frac{3 B_{e}}{(1+v)}\left[\begin{array}{ccc}
1-v & v & 0 \\
v & 1-v & 0 \\
0 & 0 & \frac{1-2 v}{2}
\end{array}\right]\left[\begin{array}{l}
d \varepsilon_{y y} \\
d \varepsilon_{z z} \\
d \varepsilon_{y z}
\end{array}\right]_{r} \& \quad d \sigma_{x x-r}=v\left(d \sigma_{y y-r}+d \sigma_{z z-r}\right)
$$

where $v[-]$ is the Poisson's ratio. Based on the strain compatibility equation, the restrained strain increment is the total strain increment $d \boldsymbol{\varepsilon}[-]$, minus the free strain increment $d \boldsymbol{\varepsilon}_{f r}[-]$ :

$$
d \varepsilon_{r}=d \varepsilon-d \varepsilon_{f r}
$$


Accepted version. Paper published as: Ghourchian et al., On the mechanism of plastic shrinkage cracking in fresh cementitious materials. Cem Concr Res (2019) 115: 251-263

https://doi.org/10.1016/j.cemconres.2018.10.015

The free strain increments $\Delta \varepsilon_{y y-f r}$ and $\Delta \varepsilon_{z z-f r}$ obtained from the plastic shrinkage model in [15], were utilized in eq. (8). Solving the coupled equations (8), (7), and (6) with the structural boundary conditions (see Fig. 3), yields the restraint stress increments. The equations were solved using the structural mechanics module of COMSOL Multiphysics ${ }^{\circledR}$. The evolution of stresses in time was calculated by integrating $\left(\Delta \boldsymbol{\sigma}_{r} / \Delta t\right)$ over time. $\Delta t[\mathrm{~s}]$ is the time increment, which in this study was $60 \mathrm{~s}$. Eventually, the principal restraint stresses were added to the principal (hydrostatic) effective stresses, to obtain the overall effective stress tensor [96]. Failure thus includes the effect of effective stress as postulated originally by Terzaghi [93], see also [96]. Failure occurs when the stress path goes beyond the failure limit, which is explained in the next section.

The experimental determination of the Poisson's ratio of fresh concrete is a very challenging task. In a study on 3-D consolidation of saturated clay, a value of Poisson's ratio of 0.4 was found at the solids percolation threshold [97]. A similar value was reported for saturated clays also by Bowles [98]. Lower values of Poisson's ratio are reported for unsaturated clays (0.1-0.3) or sandy clays (0.2-0.3) [98]. Also, values around 0.3 were reported for early-age cement paste after setting [99]. In lack of direct experimental evidence, in particular considering the effect of drying and capillary pressure stiffening, a constant Poisson's ratio equal to $1 / 3$ was assumed in the simulations.

\subsection{Failure criteria}

Failure is assessed based on two criteria: Bresler-Pister and Rankine. Here, the applied failure criteria are briefly presented, while the derivation of the equation describing the failure curves is presented in Appendix A.

\subsubsection{Bresler-Pister criterion}

The Bresler-Pister criterion [18,33,34] (see Fig. 2 and eq. (9)) was initially developed to model the resistance of hardened concrete under multiaxial stresses. It was developed as an extension of DruckerPrager shear failure model for soils $[33,37]$. Similarly as in the Drucker-Prager model with cap failure $[36,100]$, the Bresler-Pister criterion used here also accounts for the hydrostatic model of failure (corresponding to the cap in the failure curve). The derivation of the equation of the failure curve of the Bresler-Pister model presented in Fig. 2 and eq. (9) based on the experimentally-determined compressive pseudo-elastic stress limit explained in section 2 and on fresh concrete's shear strength properties is presented in Appendix A. According to the Bresler-Pister criterion with parameters derived in Appendix A, the failure can be written in terms of stress invariants: 
Accepted version. Paper published as: Ghourchian et al., On the mechanism of plastic shrinkage cracking in fresh cementitious materials. Cem Concr Res (2019) 115: 251-263

https://doi.org/10.1016/j.cemconres.2018.10.015

$$
\sqrt{J_{2}}=\left(-\frac{C+3 p_{p e l-c} \tan \phi}{9 p_{p e l-c}^{2}}\right) I_{1}^{2}+I_{1} \tan \phi+C
$$

where, $J_{2}\left[\mathrm{~Pa}^{2}\right]$ and $I_{1}[\mathrm{~Pa}]$ are the principal stress invariants (see Appendix A), $C[\mathrm{~Pa}]$ and $\phi[\mathrm{Pa}]$ are the shear strength material properties in the Drucker-Prager failure criterion that are related to $c[\mathrm{~Pa}]$ (cohesion) and $\varphi$ [degree] (angle of internal friction) in the Mohr-Coulomb criterion $[18,100]$ (see eqs. (A-10) and (A-11)). The angle of internal friction for fresh mortar was found to be between 11 and $42^{\circ}$ [101]. Here, the angle was assumed as the average value of the latter range, equal to $27^{\circ}$, close to the value of $31.5^{\circ}$ proposed for sand-to-cement $(\mathrm{s} / \mathrm{c})$ ratio of 2 and water-to-cement ratio of 0.45 in [101]. Increasing the aggregate content increases the friction angle [101,102]. Furthermore, based on the conclusions of [103], it was assumed that the internal friction angle remains constant, while cement hydration increases the cohesion.

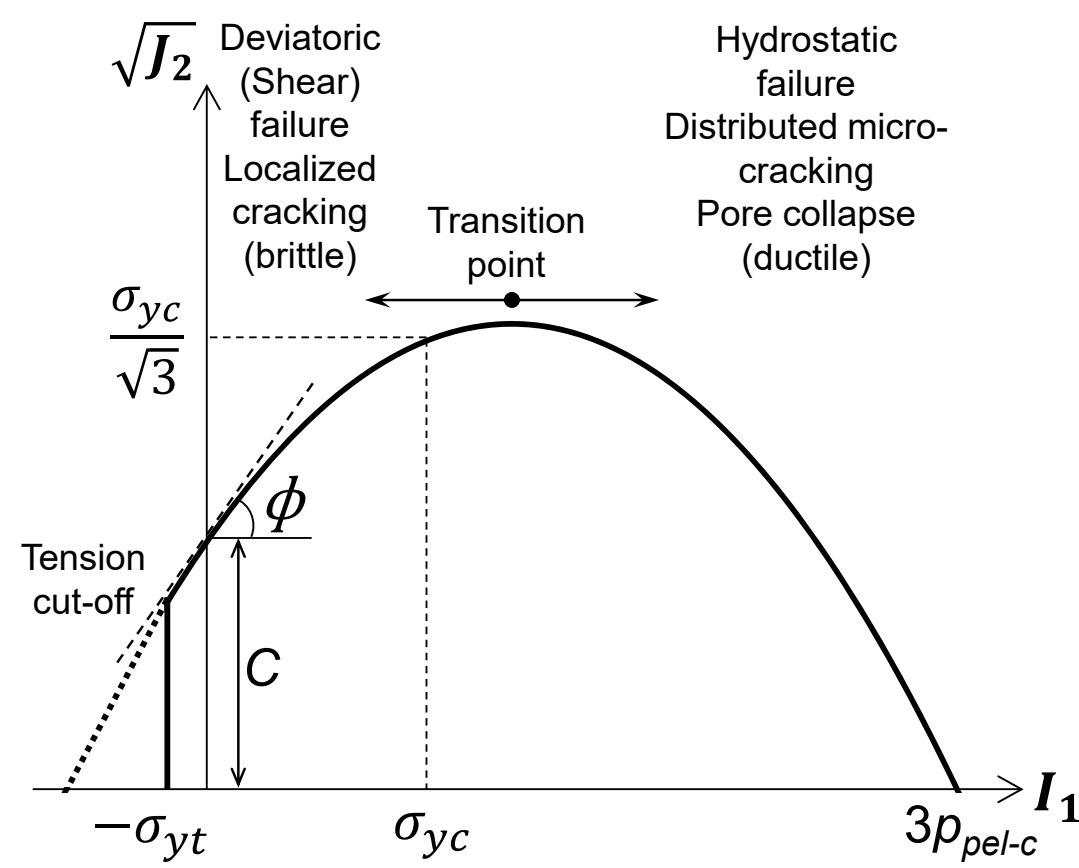

Fig. 2. Bresler-Pister failure model for cementitious materials with material parameters adapted according to the Drucker-Prager model including the tension cut-off and cap failure. The axes are not scaled equally. Compressive stresses are assumed positive.

Mind that $C$ and $p_{\text {pel-c }}$ evolve due to the hydration and capillary pressure. The effect of capillary pressure (i.e. isotropic stress) on the cohesion [96] was taken into account, since the pseudo-elastic limit was obtained by considering the effect of the isotropic stress on the stress-strain curve (see section 2). The evolution of the compressive pseudo-elastic limit was estimated in section 2 according to the data 
Accepted version. Paper published as: Ghourchian et al., On the mechanism of plastic shrinkage cracking in fresh cementitious materials. Cem Concr Res (2019) 115: 251-263

https://doi.org/10.1016/i.cemconres.2018.10.015

presented in [15]. The evolution of the cohesion can be linked to the development of the compressive pseudo-elastic limit by assuming a linear relationship between the increments of $p_{p e l-c}$ and the cohesion. In lack of experimental data, ratios between the two increments $d C / d p_{p e l-c}$ equal to $[0.2,0.3,0.4]$ were employed in this study. Higher values for the latter ratio would imply that the tensile strength of concrete becomes too high compared to the compressive strength. The initial value of the cohesion was assumed as zero following [103].

\subsubsection{Rankine criterion}

Rankine's failure theory states that a brittle material fails when the maximum principal normal stress exceeds the tensile strength during a uniaxial stress test $[35,104]$. The tensile strength was estimated according to Griffith's failure envelope, as explained in the previous section, and was compared with the tensile principal stress.

\subsubsection{Boundary conditions and mesh size}

Fig. 3 shows the mesh and boundary conditions. To avoid the stress singularity, the sharp edges were substituted by fillets of radius $2 \mathrm{~mm}$. The radius was chosen equal to half of the maximum aggregate diameter $(D=4 \mathrm{~mm})$. In Fig. 3, the first and second word written on the boundaries in the figure belong to the boundary condition of the structural mechanics (explained in this study) and moisture transfer (explained in detail in [15]) modules, respectively. The mesh was generated by the utilized FEM (Finite Element Method) software, COMSOL Multiphysics ${ }^{\circledR}$.

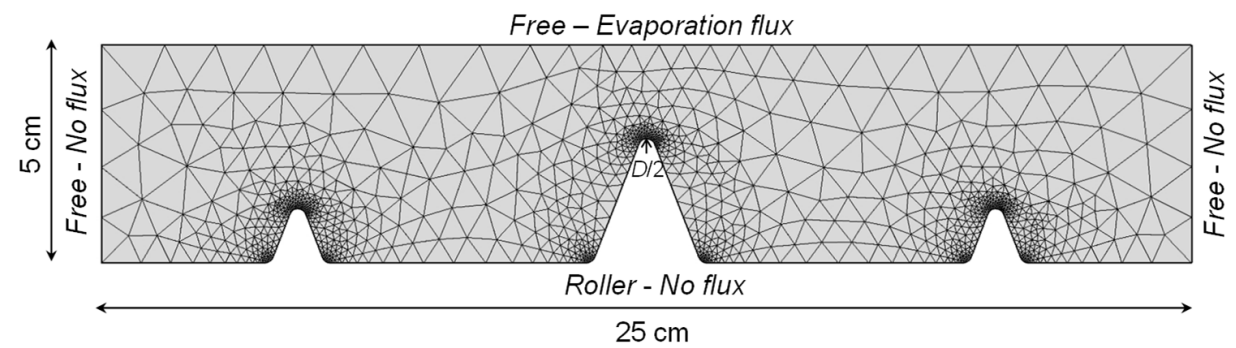

Fig. 3. Mesh sizes and boundary conditions. $D$ is the maximum aggregate diameter. The implemented mesh consists of 1994 triangular finite elements.

In the free boundary condition, the displacement is allowed in all directions. For boundaries with rollers, the displacement is not allowed in the direction normal to the surface:

$$
\boldsymbol{n} \cdot \boldsymbol{u}=0
$$


Accepted version. Paper published as: Ghourchian et al., On the mechanism of plastic shrinkage cracking in fresh cementitious materials. Cem Concr Res (2019) 115: 251-263

https://doi.org/10.1016/j.cemconres.2018.10.015

where $\boldsymbol{u}$ is the displacement vector and $\boldsymbol{n}$ is the vector normal to the surface. No flux means that the flux according to the Darcy-Buckingham equation towards the normal direction of the surface is equal to zero:

$$
-\boldsymbol{n} \cdot \nabla\left(\psi_{p}+\rho_{f} g y\right)=0
$$

where $y[\mathrm{~m}]$ is the elevation and $\rho_{f}\left[\mathrm{~kg} / \mathrm{m}^{3}\right]$ is the pore fluid density. The evaporative flux is the evaporation rate obtained experimentally by measuring the mass changes of the sample. Initially, when the bleeding rate $(b)$ is higher than the evaporation rate of free water $(e)$, water accumulates at the surface (surface pores stay saturated) and Dirichlet boundary condition are applied on the wet surface, eq. (12):

$$
\psi_{p}=0
$$

After the cumulative bleeding and evaporated water curves intersect as shown in Fig. 4 (the pores at the surface start desaturating), the latter boundary condition is replaced with the flux determined from mass measurements (Neumann boundary condition).

The initial values are:

If $e \geq b$

$$
\psi_{p}=\rho_{c} g(h-z)
$$

immediately after casting and $\psi_{p}=\rho_{f} g(h-z)$ immediately at the end of the bleeding state

If $b>e$ :

$$
\psi_{p}=\rho_{c} g(h-z)
$$

\section{Bleeding and drying states}

Fig. 4 shows the plastic shrinkage physical states after concrete casting at $t_{c}[\mathrm{~min}]$. The end of the bleeding state can be estimated as the time instant when the cumulative bleeding intersects the mass loss due to evaporation [105]. In this study, the evaporation rate was measured experimentally and bleeding was simulated according to the procedure described in [89]. 
Accepted version. Paper published as: Ghourchian et al., On the mechanism of plastic shrinkage cracking in fresh cementitious materials. Cem Concr Res (2019) 115: 251-263

https://doi.org/10.1016/j.cemconres.2018.10.015

The evaporation rate of mortars in the constant rate period was found to be very close to the evaporation of free water [38]. The evaporation rate of free water and mortars or concretes during the constant rate period, when draining of surface pores starts, can be estimated according to the analytical method proposed in [106]. After the constant rate period, the evaporation rate falls primarily due to the change in the intrinsic permeability caused by cement hydration, see $[15,107]$. In this study, first the onset of the drying state was determined. Then the restraint stresses were determined from the casting time until the end of the bleeding state, based on the free volumetric deformations. The latter stresses were added to the stresses determined in the drying state as the initial values.

The evaporation rate in the specific environmental conditions and specific concrete applied here was estimated based on the initial rate in the constant rate period and assuming that the effect of hydration-dependent microstructure (permeability) is as found for the same mortar tested in [15]. The initial rate of evaporation considered was about 0.9 of that in [15]. Consequently, the evaporation rate used in the simulations was the one in [15] multiplied by 0.9 .

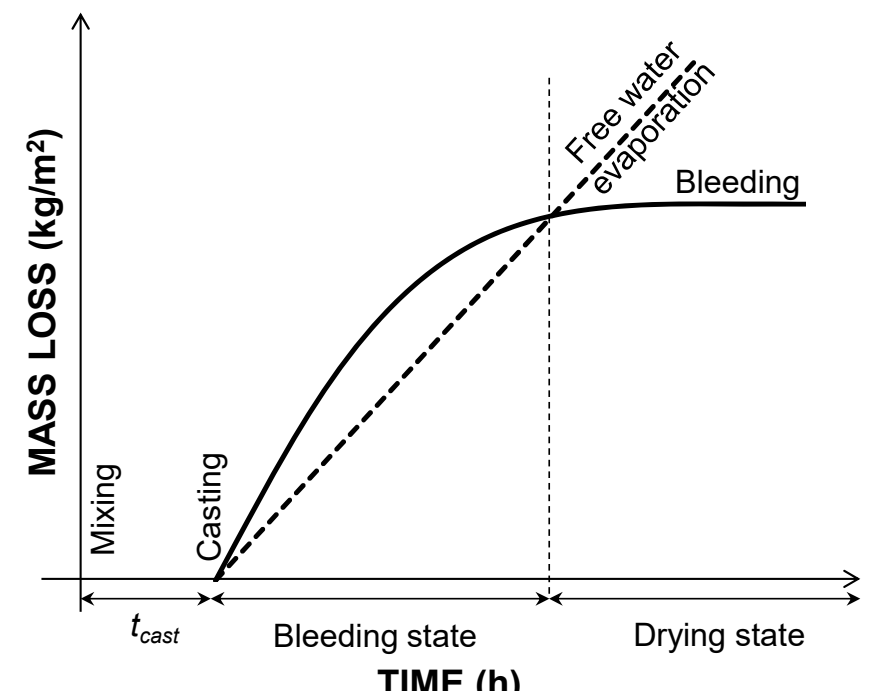

Fig. 4. States of plastic shrinkage in a fresh cementitious material [105]

\section{Experimental methods}

\subsection{Mix design}

The mortars investigated in this study, based on a Portland cement CEM I 42.5N, are shown in Table 2; they are identical to the ones tested in [15]. Two mortars were studied: a reference (REF) 
Accepted version. Paper published as: Ghourchian et al., On the mechanism of plastic shrinkage cracking in fresh cementitious materials. Cem Concr Res (2019) 115: 251-263 https://doi.org/10.1016/i.cemconres.2018.10.015

with Portland cement and a mortar with $20 \%$ by volume replacement of cement by silica fume (SF20\%). Both mortars had the same volume of aggregates (51\%) and similar water-to-binder ratio $(\mathrm{w} / \mathrm{b})$ by mass, with a small difference in the latter resulting from different densities of silica fume and cement, see Table 2. The volumetric water content was the same. Mixing took place in a 2-1 Hobart mixer. The dry materials were mixed for $30 \mathrm{~s}$. Then water was added and mixing was continued for a further $1 \mathrm{~min}$. The air content and the consistency were determined according to EN 12350-7 [108] and EN 1015-3 [109], respectively. The densities were measured by filling a $350 \mathrm{ml}$ cylindrical vessel with fresh mortars and weighing after compaction for $12 \mathrm{~s}$ on a vibrating table.

Table 2. Mix designs and physical properties of mortars

\begin{tabular}{|c|c|c|c|c|c|c|c|c|c|c|c|}
\hline 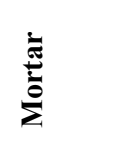 & 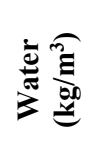 & 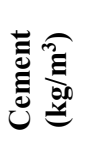 & 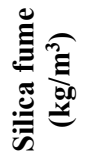 & 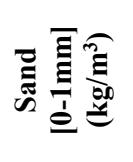 & 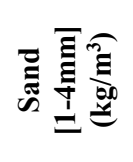 & 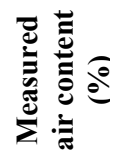 & I & 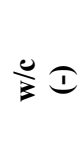 & 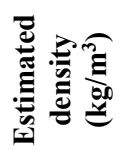 & 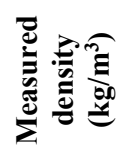 & 离 \\
\hline REF & 270 & 600 & 0 & 810 & UTd & 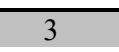 & 0.45 & 0.45 & 2220 & 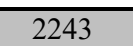 & 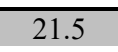 \\
\hline SF20\% & 270 & 480 & 84 & 810 & 540 & 3 & 0.48 & 0.56 & 2184 & 2164 & 15.5 \\
\hline
\end{tabular}

\subsection{Restrained plastic shrinkage test and $X$-ray radiography}

$\mathrm{X}$-ray radiography was carried out on mortars cast in a HD polyethylene mold with geometry in the imaging plane based on that prescribed by ASTM C1579 [27] (plane dimensions of the sample $\left.50 \times 250 \mathrm{~mm}^{2}\right)$, but thinner in the out-of-plane direction $(80 \mathrm{~mm})$ as to enable sufficient X-ray transmission, see Fig. 5. The fan placed over the top surface provided air flow with speed $0.9 \pm 0.2$ $\mathrm{m} / \mathrm{s}$. The room temperature and relative humidity were $25{ }^{\circ} \mathrm{C}$ and $27 \%$, respectively. The mold was filled with mortar and was compacted by manual shaking for $12 \mathrm{~s}$. The tests started $40 \mathrm{~min}$ after mixing.
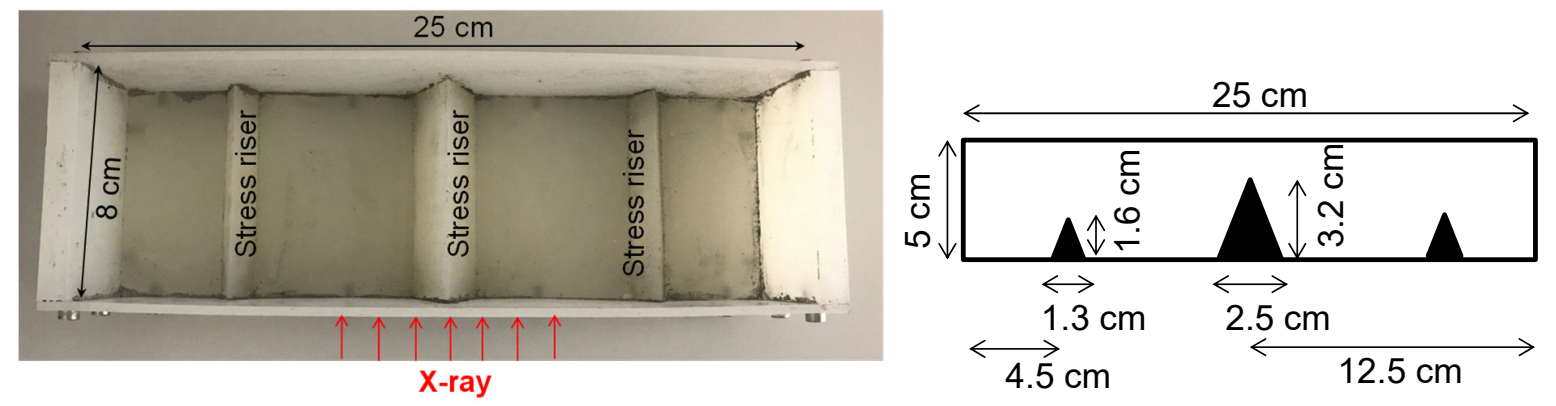

Fig. 5. Details of mold for imaging of plastic shrinkage cracking and direction of X-ray beam. 
Accepted version. Paper published as: Ghourchian et al., On the mechanism of plastic shrinkage cracking in fresh cementitious materials. Cem Concr Res (2019) 115: 251-263

https://doi.org/10.1016/i.cemconres.2018.10.015

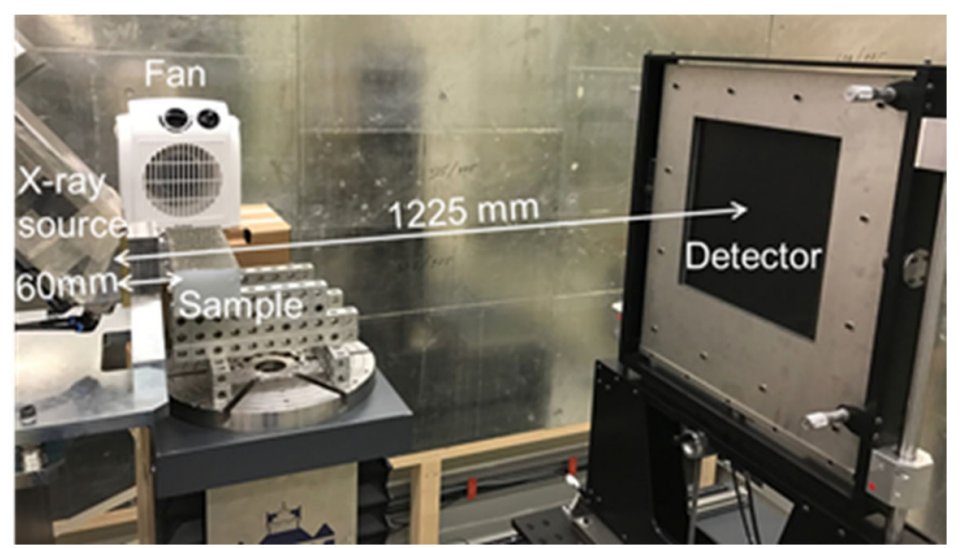

Fig. 6 X-ray radiography set-up

The specimens were imaged in radiography with the X-ray $\mu$ DETECT setup at Empa (see Fig. 6). In this instrument, the X-ray radiation is generated by a micro-focus $\mathrm{X}$-ray tube from Finetec (model FOMR 300.03Y RT) operating at an acceleration voltage of $280 \mathrm{kV}$ and a tube current of $70 \mu \mathrm{A}$. A flat panel detector from Perkin Elmer (model XRD 1611-CP3) acquired the projection images, in its full-resolution mode, corresponding to pixels of $100 \times 100 \mu \mathrm{m}^{2}$. The sample was placed as close as possible to the source, at roughly $60 \mathrm{~mm}$ from the focus, and the detector was located at a distance of $1225 \mathrm{~mm}$ from the focus, offering the magnification roughly equal to 25 . An acquisition time of $2 \mathrm{~s}$ was employed and a total of 15 images were averaged per time frame. The images were next cropped to include only the field around the central insert (stress riser) on the top of which the cracks initiate. The insert was cut out from the images. Next, the average image at the crack initiation subsequence was subtracted from the consecutive images in order to better visualize cracking.

\subsection{Determination of the pseudo-elastic limit}

To determine the pseudo-elastic limit according to the method proposed in section 2, first the parameters of eq. (1) were obtained with the following method. The experimental bulk modulus was calculated utilizing the experimentally-measured volumetric plastic shrinkage and pore pressure in [15] (equal to the effective stress in a thin sample with assumed negligible effect of gravity) and the incremental stress-strain relationship:

$$
B_{e}=\frac{\Delta \sigma_{e f f}}{\Delta \varepsilon_{v o l}}
$$


Accepted version. Paper published as: Ghourchian et al., On the mechanism of plastic shrinkage cracking in fresh cementitious materials. Cem Concr Res (2019) 115: 251-263 https://doi.org/10.1016/j.cemconres.2018.10.015

The time increment $(\Delta t)$ was identical to the time increment in the DIC measurements, 3 min, as performed in [15]. Then eq. (15), which takes into account the effect of negative pore pressure on stiffness after the solid percolation, was fitted to the experimental data by the least squares method (see Fig. 7).

$$
\begin{array}{cc}
\psi_{p} \geq \rho f g(h-z) & B_{e}=B_{b} \\
\psi_{p}<\rho_{f} g(h-z) & B_{e}=B_{b}\left[(1-\xi) \exp \left(\omega\left[\psi_{p}-\rho_{f} g(h-z)\right]\right)+\xi\right]
\end{array}
$$

The determined parameters were: $\xi=8.1$ [-], identical for both mortars, and $\omega=1.3$ and $0.6[1 / \mathrm{kPa}$, for REF and SF20\%, respectively. The latter is in line with the experimental evidence for soils [110], where it was found that $\omega$ decreases by moving from coarser to finer particle size distribution, while $\xi$ remains constant.

Following the above-mentioned parameter calibrations, the evolution of the pseudo-elastic limit was obtained by the method proposed in section 2, yielding the evolution presented in Fig. 8. As it is presented in Fig. 8, reducing the clinker content retards the evolution of the pseudo-elastic limit.

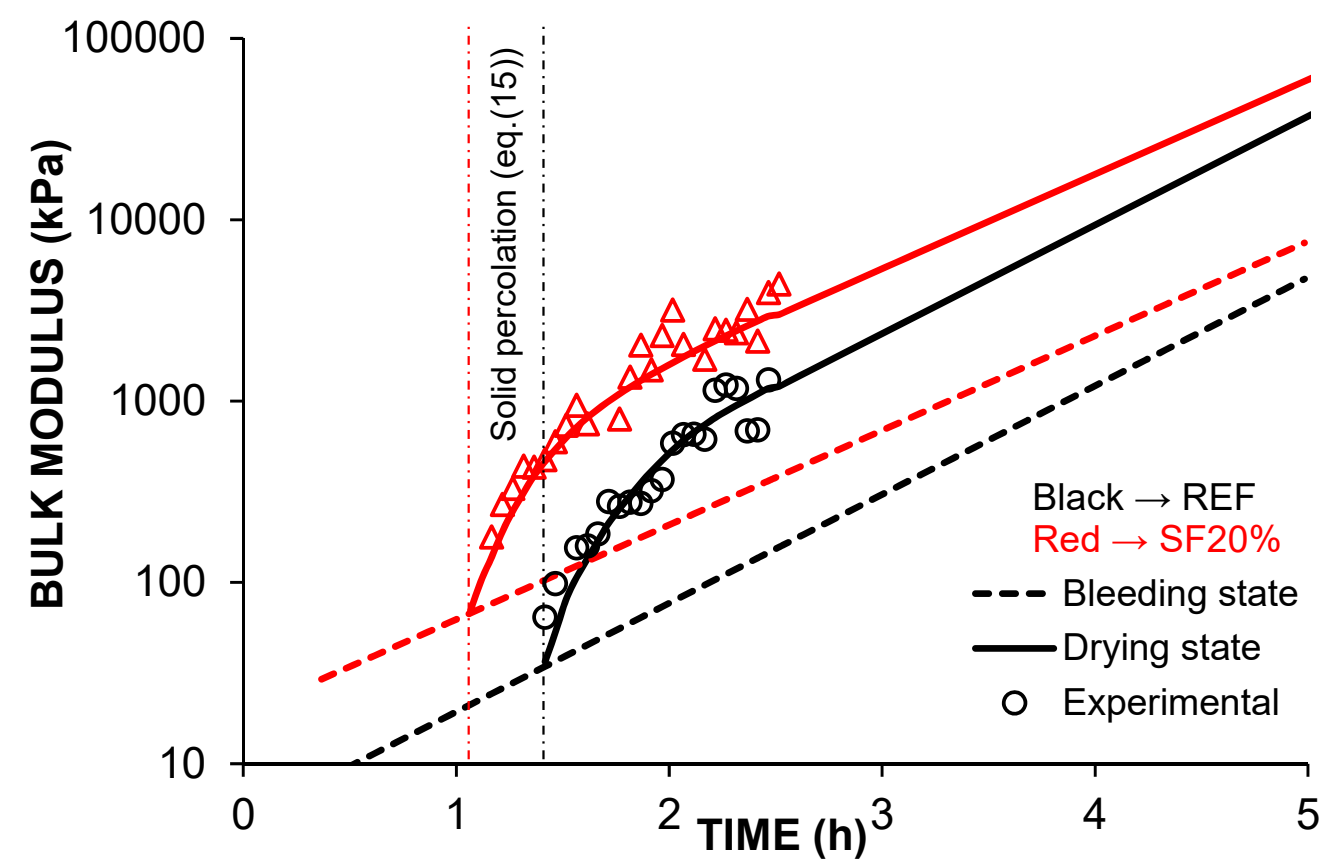

Fig. 7. Evolution of bulk modulus in the drying state, according to the experimental plastic shrinkage test data and eq. (15), performed on samples of size $250 \times 250 \times 100 \mathrm{~mm}^{3}$ in [15]. 
Accepted version. Paper published as: Ghourchian et al., On the mechanism of plastic shrinkage cracking in fresh cementitious materials. Cem Concr Res (2019) 115: 251-263

https://doi.org/10.1016/j.cemconres.2018.10.015

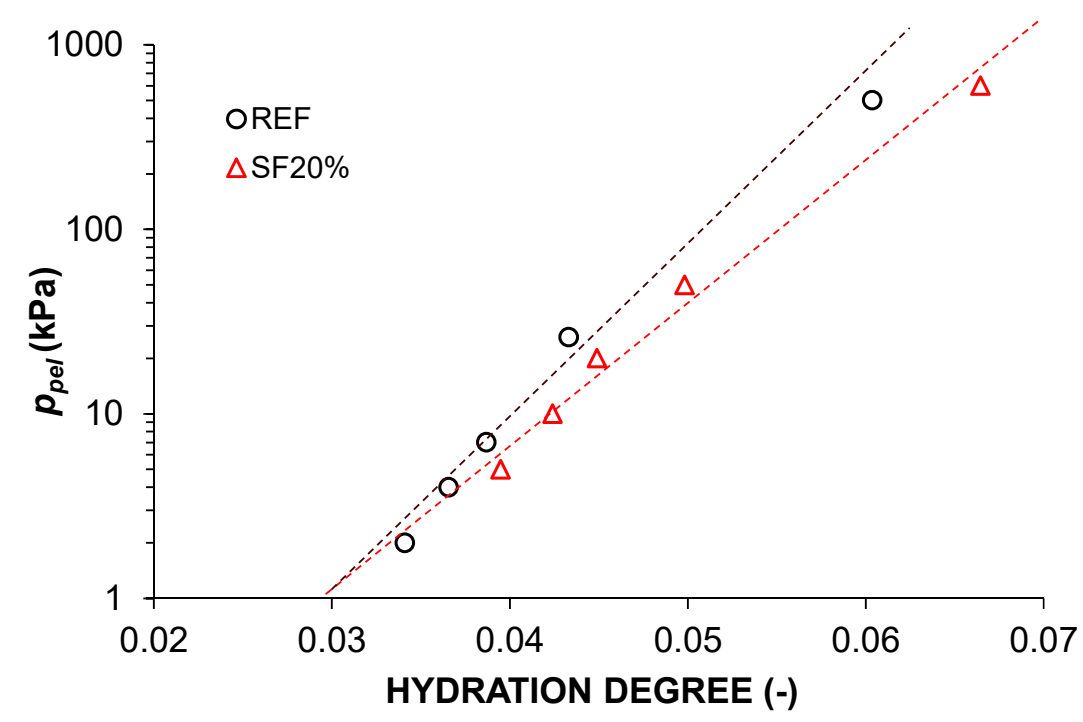

Fig. 8. Evolution of pseudo-elastic limit vs. hydration degree.

It should be mentioned that the method proposed here calculates the average values of the parameters of eq. (1) during the performed plastic shrinkage test in [15] by fitting the experimental data. As an alternative, one could explicitly determine the dependence of bulk modulus upon capillary pressure at different degrees of hydration by repeating the plastic shrinkage test on thin samples (to enable faster equilibration of pressure) at certain time intervals, similar to [15]. At each test, high wind speed needs to be provided to accelerate the evaporation. The pore pressure or the effective stress evolution can be measured by tensiometers. Furthermore, the volumetric deformation can be measured with the DIC system described in [15].

\section{Model verification}

\subsection{Evaporation and bleeding rates}

Fig. 9 shows the simulated bleeding curves and the measured evaporation rate $(0.65 \pm 0.03$ $\mathrm{kg} / \mathrm{m}^{2} \mathrm{~h}$ ). $t_{\text {cast }}$ was equal to $0.67 \mathrm{~h}$ for both tested mortars. The REF mortar experienced bleeding during $1.7 \mathrm{~h}$, due to the higher bleeding rate compared to the evaporation rate, while SF20\% entered the drying state right after the beginning of the test. Fig. 10 shows the utilized evaporation rates. 
Accepted version. Paper published as: Ghourchian et al., On the mechanism of plastic shrinkage cracking in fresh cementitious materials. Cem Concr Res (2019) 115: 251-263 https://doi.org/10.1016/j.cemconres.2018.10.015

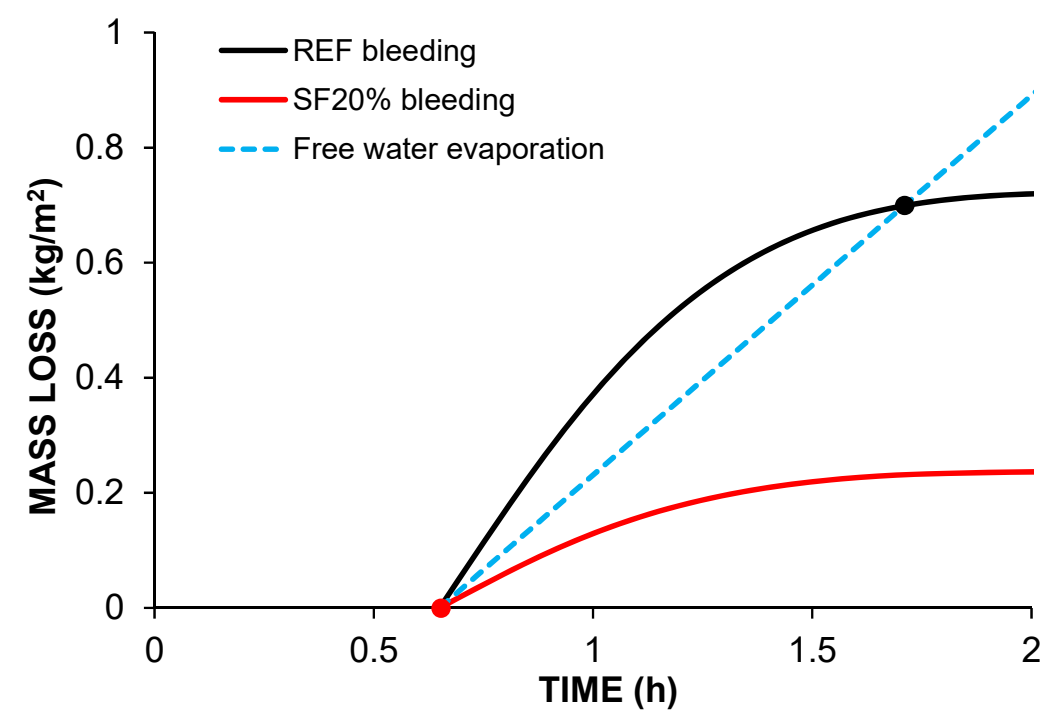

Fig. 9. Simulated bleeding and experimentally measured evaporation mass loss vs. time. Black and red dots show the beginning of the drying state for REF and SF20\%, respectively.

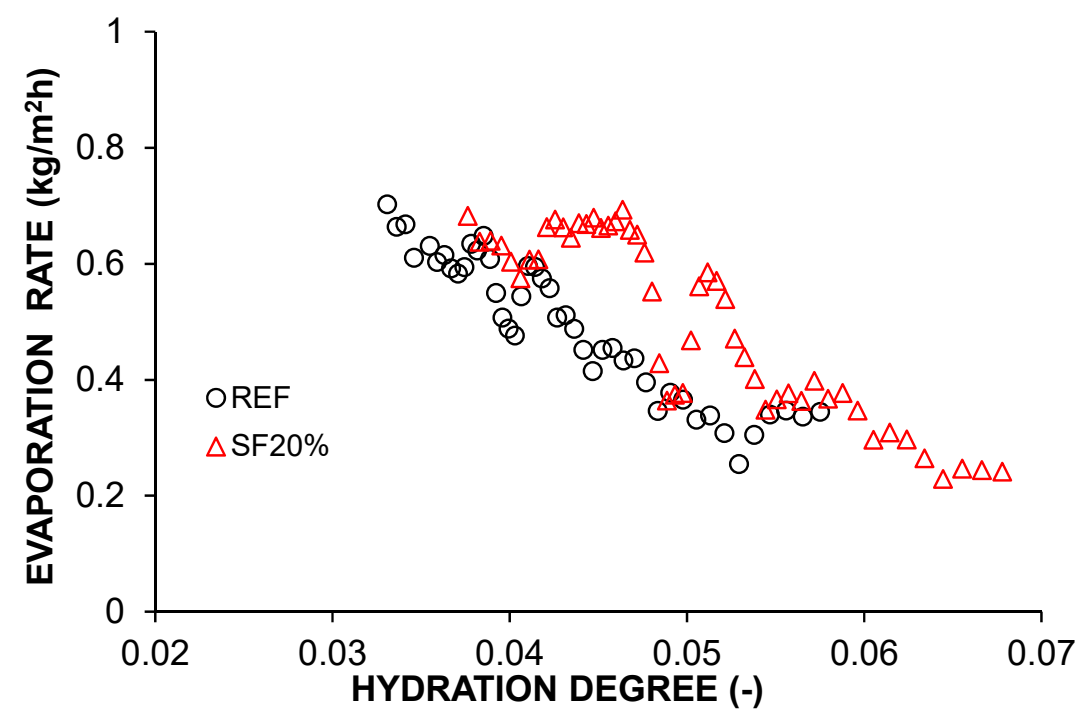

Fig. 10. Evaporation rate vs. hydration degree used in the model

\subsection{Failure}

\subsubsection{Experimental crack detection}

In Fig. 11 a time sequence of subtraction images obtained from X-ray radiography is presented. Crack initiation at the tip of the stress riser in the middle of the mold can be seen. The time shown in the pictures is from mixing time. SF20\% cracked earlier at $2.33 \mathrm{~h}$ comparing to REF at $2.75 \mathrm{~h}$. 
Accepted version. Paper published as: Ghourchian et al., On the mechanism of plastic shrinkage cracking in fresh cementitious materials. Cem Concr Res (2019) 115: 251-263

https://doi.org/10.1016/j.cemconres.2018.10.015

After crack initiation, the cracks propagated rapidly to the top surfaces. At the end of the test, in SF20\% a substantially larger crack was evident.
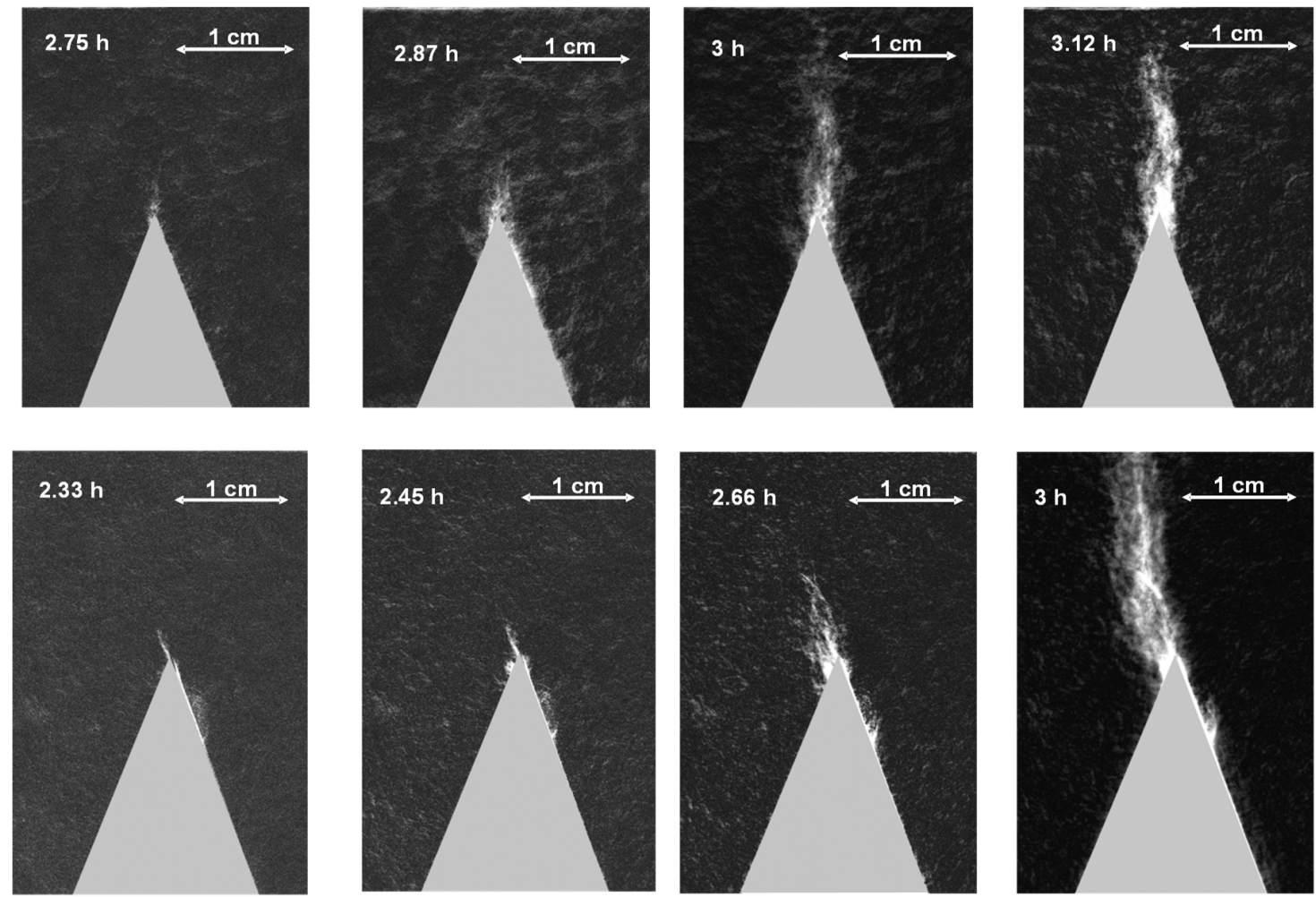

Fig. 11. Plastic shrinkage cracking initiation and propagation in the drying state for REF (above) and SF $20 \%$ (below) seen on subtraction images from X-ray radiography. The values on top left corner show the time after mixing.

\subsubsection{Modeled crack initiation}

The free shrinkage was obtained according to the model explained in [15], and was applied as input to the structural mechanics model to obtain the restraint stresses. Fig. 12 shows the restrained deformation of SF20\% (note that the deformations were qualitatively similar for both mixes) and the position of failure initiation. As expected, the failure occurred at the tip of the largest stress riser, due to the restraint stress concentration. Both failure criteria (Bresler-Pister and Rankine, see section 3.2) showed the same position and very close time of failure initiation. 
Accepted version. Paper published as: Ghourchian et al., On the mechanism of plastic shrinkage cracking in fresh cementitious materials. Cem Concr Res (2019) 115: 251-263

https://doi.org/10.1016/j.cemconres.2018.10.015

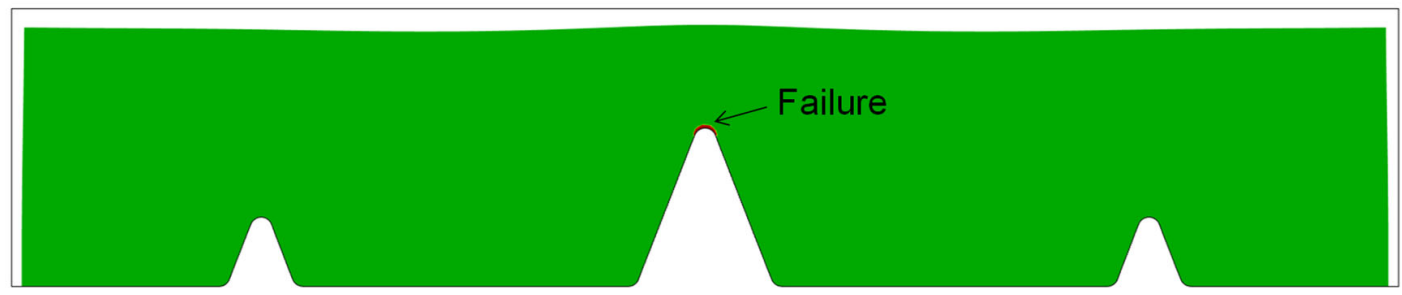

Fig. 12. Deformation of the SF20\% mortar in restrained conditions and position of failure initiation. The deformations are magnified for better visibility.

The failure is explained in detail in the next section by extracting the related average values of principal stresses and comparing them with the failure criteria.

Crack propagation has not been modeled in this work. As explained in the introduction, the failure is defined to occur due to the crack initiation. Possible approaches to crack propagation could be by FEM remeshing techniques and XFEM (Extended Finite Element Method) to simulate the occurred discontinuity $[20,111]$ or by the phase-field method, which reproduces the crack paths without introducing discontinuities on a fixed mesh [112].

\subsubsection{Crack initiation according to Bresler-Pister's criterion}

Fig. 13 and Fig. 14 show the stress development and the strength envelope at the time of failure according to the Bresler-Pister criterion. The time interval between markers is fixed at $5 \mathrm{~min}$. The rate of increment of stresses increased dramatically in the drying state, due to increase of capillary pressure that further leads to a stiffening of the bulk according to eq. (1) as also shown in Fig. 15. The failure occurs when the stress path intersects the strength envelope. Increasing the value of the strength ratio $d C / d p_{p e l-c}$ did not influence the failure time significantly. As explained in [15], the capillary pressure stiffens the bulk before the air entry, when high deformations take place in saturated conditions, accompanied by high capillary pressure at the evaporating surface (see Fig. 15). The large deformations together with stiffening accelerate the stress progress, and lead to cracking. The latter has been identified as the main mechanism of plastic shrinkage cracking in the drying state.

The model underestimated the crack initiation time for both mortars, which could be due to the over-estimated evaporation rate, since the applied wind was not uniform on the sample. The latter shows the importance of having uniform wind velocity on the samples in plastic shrinkage tests in 
Accepted version. Paper published as: Ghourchian et al., On the mechanism of plastic shrinkage cracking in fresh cementitious materials. Cem Concr Res (2019) 115: 251-263 https://doi.org/10.1016/j.cemconres.2018.10.015

order to obtain meaningful comparable experimental results [113]. Another possible reason could be the resolution of the utilized X-ray setup, which may not be able to capture the failure right at the time of initiation. The modelled failure occurred earlier for SF $20 \%$, which agrees well with the experimental data.

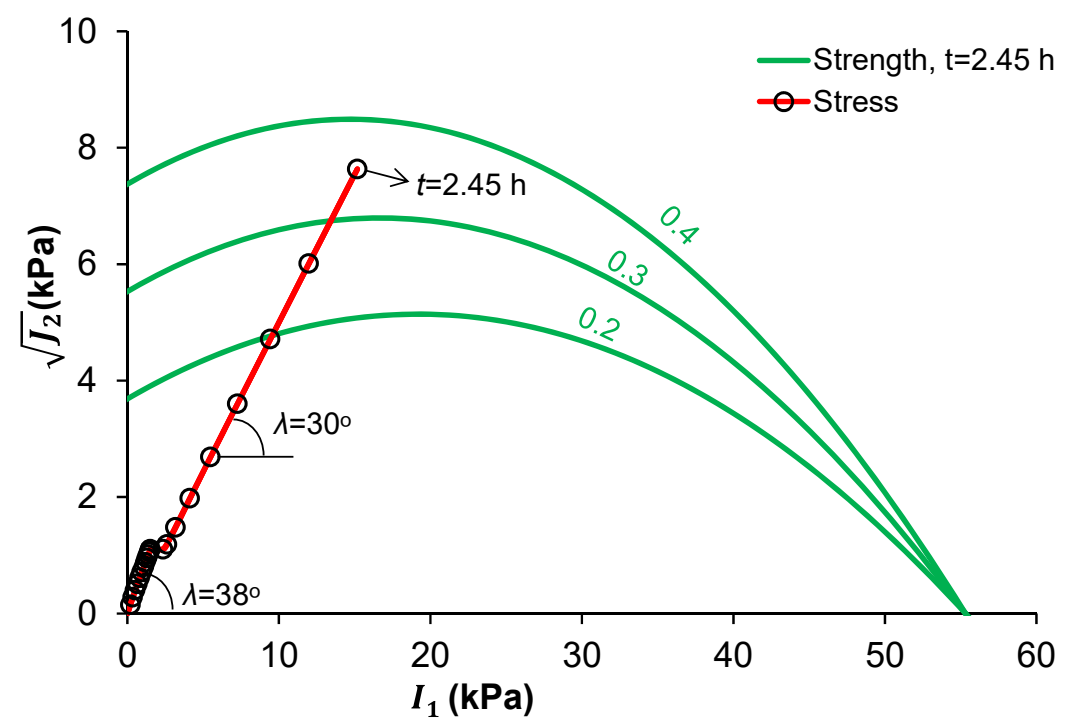

Fig. 13. Stress path and the strength envelopes for REF at the time of failure according to Bresler-Pister Criterion. The numbers next to the curves refer to the ratio $d C / d p_{\text {pel-c }}($ see section 3.2.1)

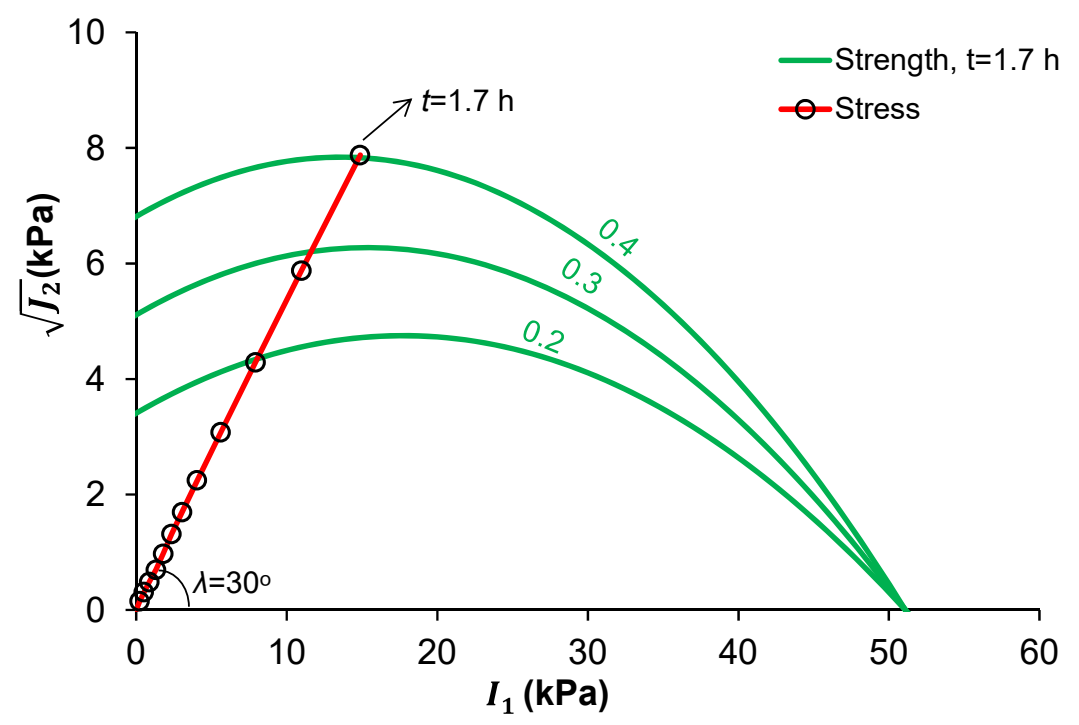

Fig. 14. Stress path and the strength envelopes for SF20\% at the time of failure according to BreslerPister Criterion. The numbers next to the curves refer to the ratio dC/dppel-c (see section 3.2.1) 
Accepted version. Paper published as: Ghourchian et al., On the mechanism of plastic shrinkage cracking in fresh cementitious materials. Cem Concr Res (2019) 115: 251-263

https://doi.org/10.1016/j.cemconres.2018.10.015

The angle of stress path ( $\lambda$ [degree]) was identical for both mortars during the drying state, about $30^{\circ}$. This angle was higher for the bleeding state for the REF mortar, $38^{\circ}$. The latter is due to the fact that in the bleeding state the deformations are solely in the vertical direction. Therefore, a higher cohesion increment is needed in order to move the failure to the pore collapse regime, compared to the drying state.

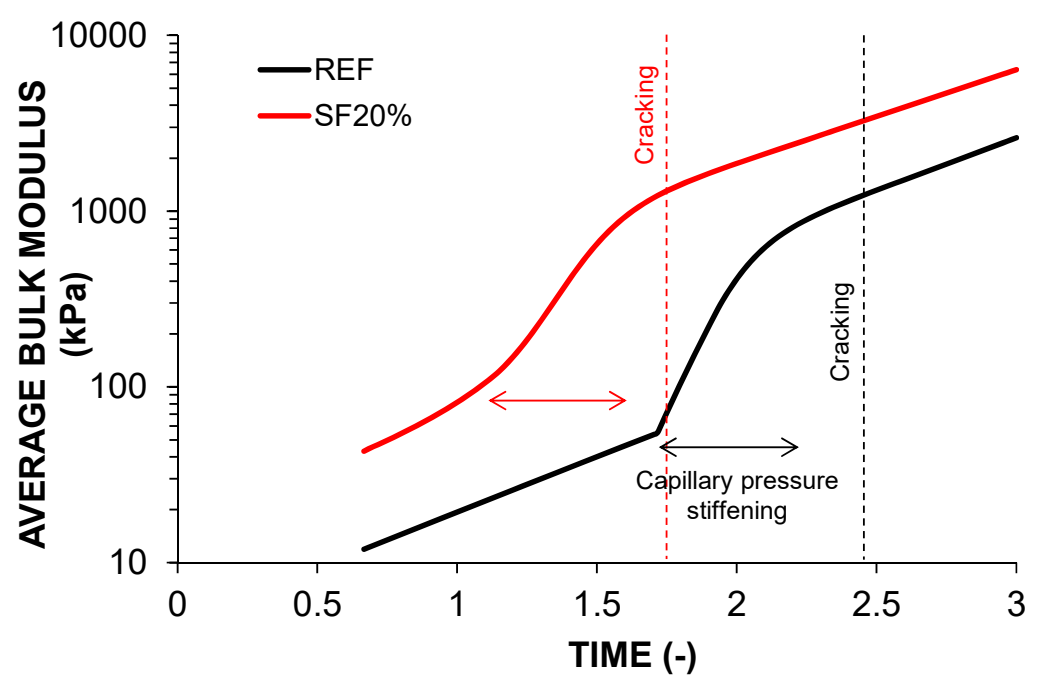

Fig. 15. Simulated bulk modulus evolution. The shown periods indicate the secondary exponential evolution of the bulk modulus due to the capillary pressure stiffening in the drying state.

\subsubsection{Crack initiation according to Rankine's criterion}

Fig. 16 and Fig. 17 show the development of the principal stresses over time and their direction at the position of the failure on the tip of the largest stress riser. The principal tensile stress developed in the horizontal direction, leading to the initiation of the brittle crack, perpendicularly to the horizontal axis [1], as also obtained in the experimental test. The time of failure indicated by Rankine's criterion agrees well with the Bresler-Pister criterion. The crack initiation occurring earlier in the SF mortar (while still in the dormant period of hydration) may further lead to wider crack opening compared to the REF mortar, in which crack initiation occurred in the acceleration period. This is in agreement with the findings of [107], where it was observed that faster hydration (in cements with higher clinker content or finer cements) leads to smaller crack opening. 
Accepted version. Paper published as: Ghourchian et al., On the mechanism of plastic shrinkage cracking in fresh cementitious materials. Cem Concr Res (2019) 115: 251-263 https://doi.org/10.1016/j.cemconres.2018.10.015

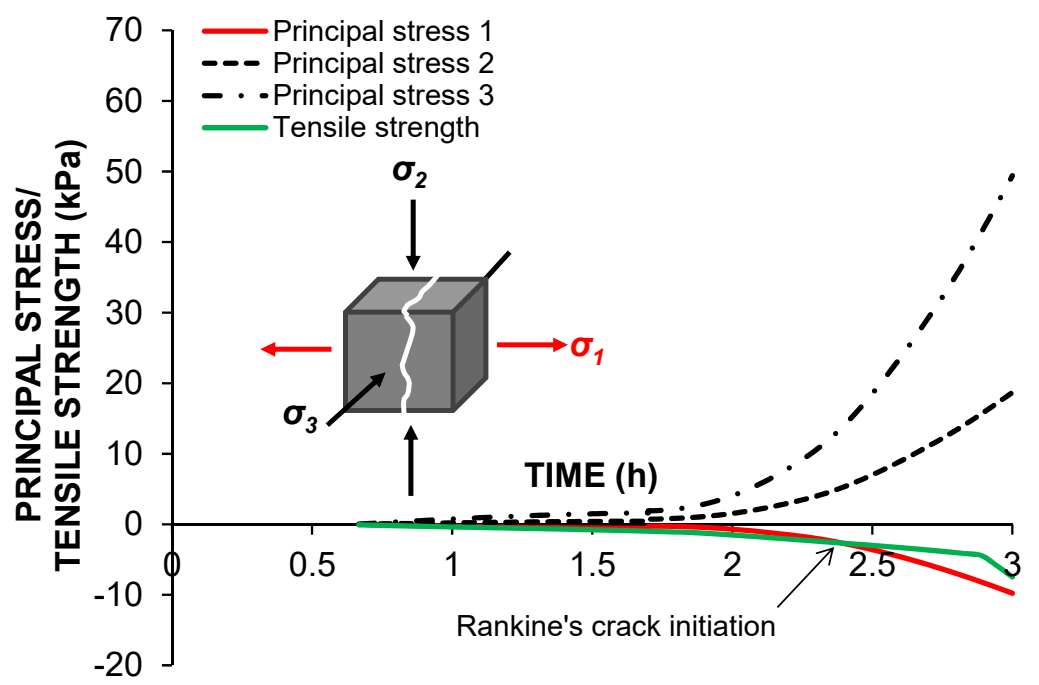

Fig. 16. Principal stresses vs. time for REF.

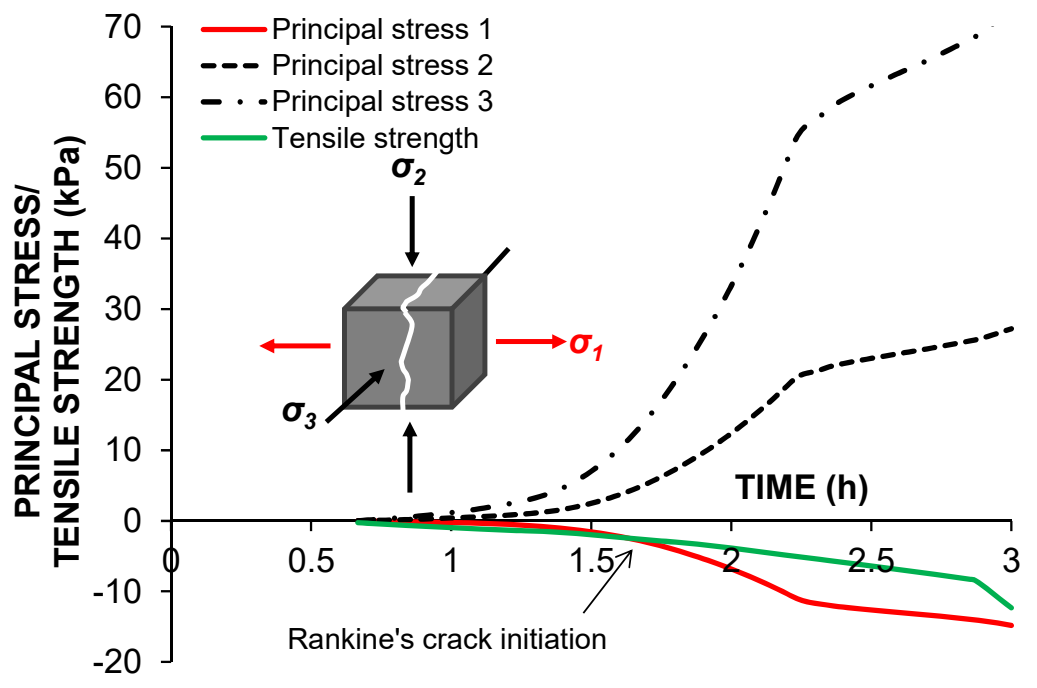

Fig. 17. Principal stresses vs. time for SF20\%.

\subsection{Horizontal and vertical shrinkage}

Fig. 18 shows the simulated free plastic shrinkage for both mortars, with in addition a line that indicates the predicted time instant of crack initiation. REF had delayed failure initiation due to the initial bleeding, which delayed the initiation of the capillary pressure and horizontal shrinkage. The crack initiation occurred sometime after the onset of horizontal shrinkage, as obtained in [107]. According to the simulated shrinkage, crack initiation occurred when the horizontal shrinkage was 0.003 [-] for both mortars. The latter implies that the strength does not play an important role in the initiation of plastic shrinkage cracking. The plastic shrinkage crack initiation is controlled by 
Accepted version. Paper published as: Ghourchian et al., On the mechanism of plastic shrinkage cracking in fresh cementitious materials. Cem Concr Res (2019) 115: 251-263

https://doi.org/10.1016/j.cemconres.2018.10.015

the capillary pressure or in the other words the horizontal shrinkage. Therefore, the best method for controlling the plastic shrinkage is to reduce the capillary pressure or the horizontal shrinkage development. On the contrary, crack opening can be reduced by using cements with faster hydration.

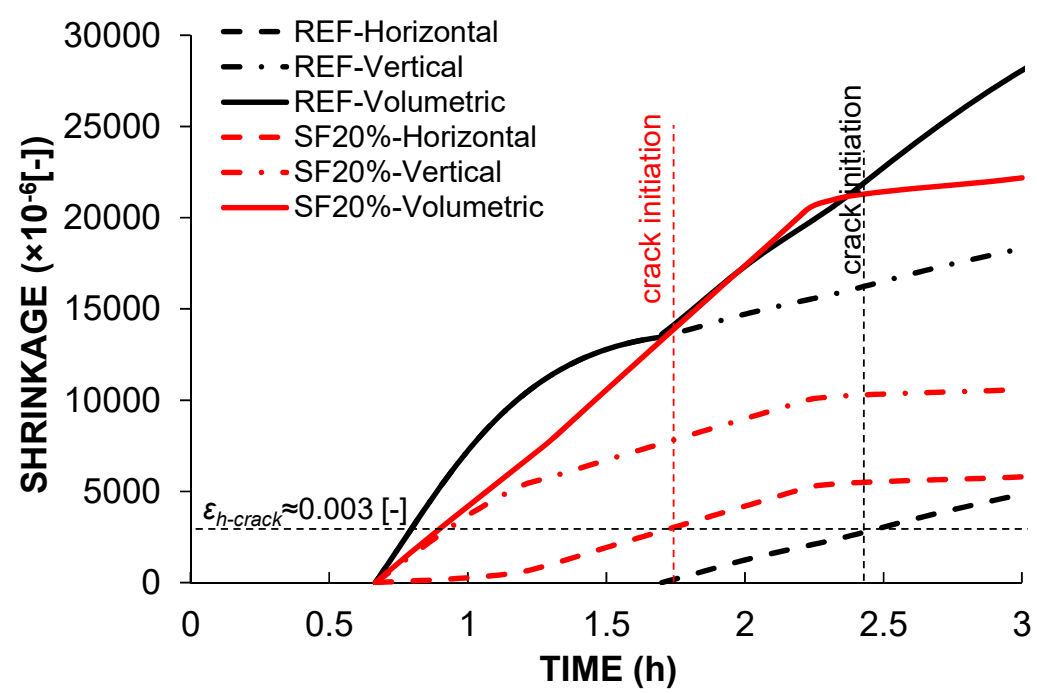

Fig. 18. Simulated free plastic shrinkage vs. time.

\section{Discussion}

As shown in the previous section, the angle of stress path in the Bresler-Pister criterion was similar for both mortars in the drying state. Furthermore the failure occurred close to the von Mises envelope, in the maximum distortion energy due to the confinement brought by the capillary pressure (see Fig. 19). Reminding that the horizontal axis in Fig. 19 represents solely the isotropic stresses (i.e. capillary pressure according to eq. (5)) and the $I_{l}$ invariant is zero for the deviatoric stress tensor (i.e. traceless) [114], one can derive a safe pressure limit ( $\left.p_{c \text {-safe }}[\mathrm{Pa}]\right)$, based on the utilized ASTM geometry, considering that the failure occurs when:

$$
p_{c}>p_{c-s a f e}=\frac{\sigma_{c y}}{3}
$$


Accepted version. Paper published as: Ghourchian et al., On the mechanism of plastic shrinkage cracking in fresh cementitious materials. Cem Concr Res (2019) 115: 251-263 https://doi.org/10.1016/j.cemconres.2018.10.015

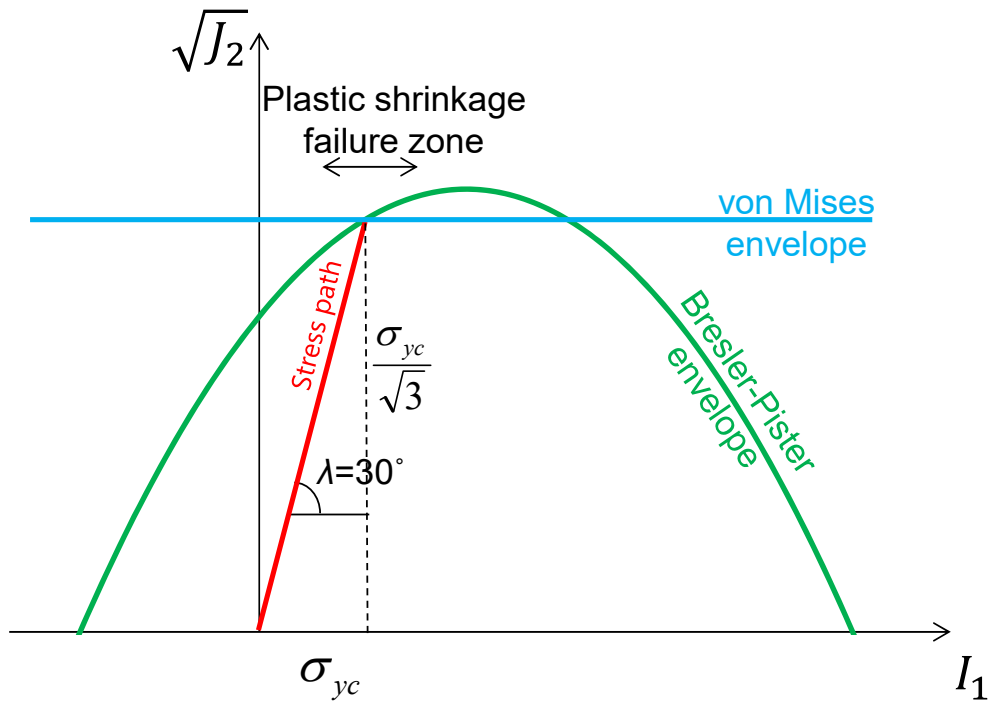

Fig. 19. Plastic shrinkage failure zone

$\sigma_{c y}$ is obtainable by eq. (A-12) and is related to the compressive pseudo-elastic limit and cohesion or tensile strength. By monitoring the capillary pressure development at the construction site [115] and applying the necessary actions (e.g. external curing), it is possible to keep the capillary pressure always below the safe limit to avoid plastic shrinkage cracking (see Fig. 20). It is worthwhile to mention that the stated limit does not cover the cracks due to bleeding (also called plastic settlement cracks), suggested as a cracking mechanism in deep elements due to the differential settlement [44].

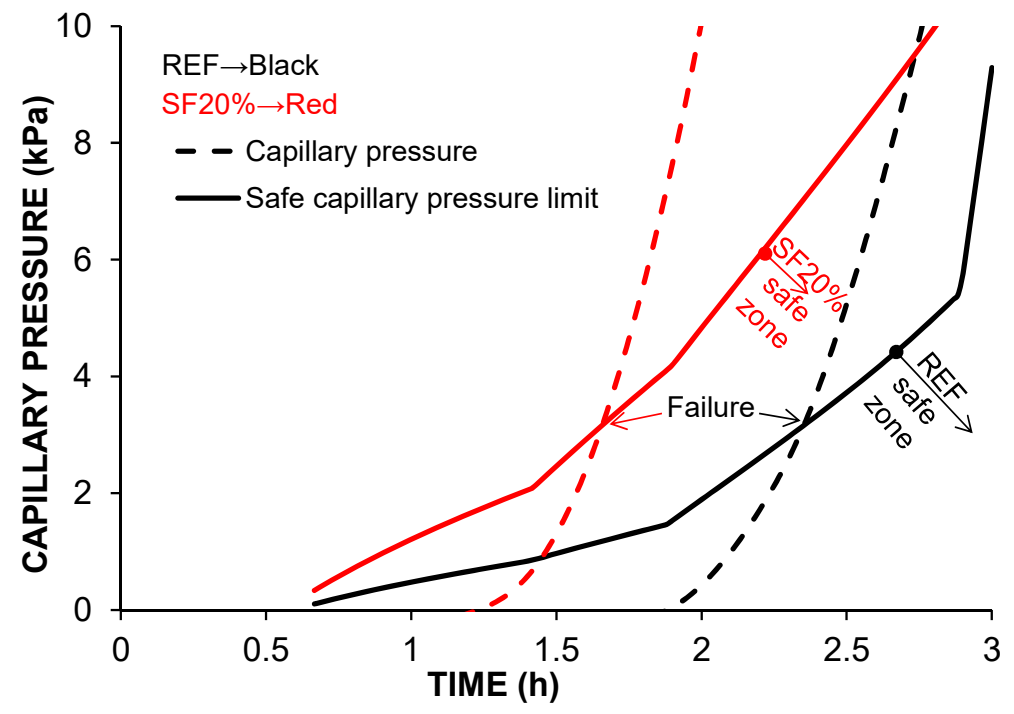


Accepted version. Paper published as: Ghourchian et al., On the mechanism of plastic shrinkage cracking in fresh cementitious materials. Cem Concr Res (2019) 115: 251-263

https://doi.org/10.1016/j.cemconres.2018.10.015

Fig. 20. Evolution of safe capillary pressure limit and simulated capillary pressure vs. time.

\section{Conclusions}

The simulated capillary pressure increment in fresh cementitious materials and the resulting plastic shrinkage (see [15]) were used to model the overall effective stress development in a modified ASTM test. The failure was modeled utilizing the Bresler-Pister and Rankine failure criteria. The material parameters were adapted according to the Drucker-Prager and Griffith's model. The modelled crack initiation was validated against experiments, in which the crack initiation was identified by X-ray radiography.

The mechanism of plastic shrinkage failure (cracking) in the drying state can be summarized as follows. The rapid evaporation of water from surface pores, while the whole body is still saturated, results in corresponding high deformations. Evaporation from the surface pores causes formation of menisci in these pores and the rise of capillary pressure. The capillary pressure causes a dramatic increment of the stiffness, which further leads to a corresponding increase of stresses. When these stresses exceed the failure limit, cracking initiates.

A safe capillary pressure limit was proposed according to the obtained stress path for plastic shrinkage failure and the strength properties at failure time to be used as a safe pressure limit benchmark. It is found that substitution of cement with silica fume moves the failure time to the dormant period, making the concrete more susceptible to plastic shrinkage cracking.

\section{Acknowledgements}

The authors thank Dr. Michele Griffa, Empa, for critical reading of this manuscript.

\section{Appendix A: Failure envelope parameters}

To link the material properties of the Bresler-Pister model (eq. (A-1)) [33] to the compressive pseudo-elastic limit that was obtained experimentally in this study (see section 2), first the shear strength parameters of fresh concrete were determined by considering the analogy of pure shear failure with the Drucker-Prager model [36,100], and further assuming that the failure under isotropic stress corresponds to the pseudo-elastic limit.

The Bresler-Pister criterion is expressed in eq. (A-1) 
Accepted version. Paper published as: Ghourchian et al., On the mechanism of plastic shrinkage cracking in fresh cementitious materials. Cem Concr Res (2019) 115: 251-263

https://doi.org/10.1016/j.cemconres.2018.10.015

$$
\sqrt{J_{2}}=A_{1} I_{1}^{2}+A_{2} I_{1}+A_{3}
$$

where and $A_{1}[1 / \mathrm{Pa}], A_{2}[-]$ and $A_{3}[\mathrm{~Pa}]$ are the material parameters and $J_{2}\left[\mathrm{~Pa}^{2}\right]$ and $I_{1}[\mathrm{~Pa}]$ are the principal stress invariants:

$$
\begin{gathered}
J_{2}=\frac{1}{6}\left[\left(\sigma_{1}-\sigma_{2}\right)^{2}+\left(\sigma_{2}-\sigma_{3}\right)^{2}+\left(\sigma_{3}-\sigma_{1}\right)^{2}\right] \\
I_{1}=\sigma_{1}+\sigma_{2}+\sigma_{3}
\end{gathered}
$$

where $\sigma_{1}[\mathrm{~Pa}], \sigma_{2}[\mathrm{~Pa}]$ and $\sigma_{3}[\mathrm{~Pa}]$ are the principal effective stresses.

In order to determine the parameters of eq. (A-1), consider the Drucker-Prager failure criterion with the parameters commonly used in failure of soils:

$$
\sqrt{J_{2}}=I_{1} \tan \phi+C
$$

with $C[\mathrm{~Pa}]$ and $\phi[\mathrm{Pa}]$ being the shear strength material properties.

Assuming that the failure limit of Bresler-Pister (eq. (A-1)) and Drucker-Prager (eq.(A-4)) match when the material is purely under shear stress (pure distortion, $I_{l}=0$ ), one can write (see also Fig. 2):

$$
\begin{gathered}
I_{1}=0 \Rightarrow \sqrt{J_{2}}=A_{3}=C \\
I_{1}=0 \Rightarrow \frac{\partial \sqrt{J_{2}}}{\partial I_{1}}=A_{2}=\tan \phi
\end{gathered}
$$

The remaining parameter $A_{l}$, is obtained considering that the material fails under pure compressive isotropic stress $\left(J_{2}=0\right)$ at the compressive pseudo-elastic limit $\left(p_{\text {pel-c }}[\mathrm{Pa}]\right)$ :

$$
\sqrt{J_{2}}=0 \Rightarrow 0=A_{1}\left(3 p_{p e l-c}\right)^{2}+3 p_{p e l-c} \tan \phi+C=0 \Rightarrow A_{1}=-\frac{C+3 p_{p e l-c} \tan \phi}{9 p_{p e l-c}^{2}}
$$

Therefore the final form of the Bresler-Pister criterion used in modelling of failure takes the form as presented also in eq. (9): 
Accepted version. Paper published as: Ghourchian et al., On the mechanism of plastic shrinkage cracking in fresh cementitious materials. Cem Concr Res (2019) 115: 251-263

https://doi.org/10.1016/j.cemconres.2018.10.015

$$
\sqrt{J_{2}}=\left(-\frac{C+3 p_{p e l-c} \tan \phi}{9 p_{p e l-c}^{2}}\right) I_{1}^{2}+I_{1} \tan \phi+C
$$

The shear failure material properties in the Drucker-Prager model are related to the ones in MohrCoulomb criterion according to the following equations $[18,116]$ :

$$
\begin{array}{r}
C=\frac{6 c \cos \varphi}{\sqrt{3}(3+\sin \varphi)} \\
\phi=\tan ^{-1}\left(\frac{2 \sin \varphi}{\sqrt{3}(3+\sin \varphi)}\right)
\end{array}
$$

In the failure curve in Fig. 2, $\sigma_{y c}[\mathrm{~Pa}]$ represents the uniaxial compressive (yield) strength [117] for which the material has the maximum capacity for deviatoric stresses close to vertex yielding [36], the transition surface where the von Mises criterion $\left(\sqrt{J_{2}}=\frac{\sigma_{y c}}{\sqrt{3}}\right)[118,119]$ intersects with the Bresler-Pister envelope. At the left and right side of the vertex yielding, shear and cap failure occurs, respectively. The shear failure is a brittle failure in the form of discrete cracking. The cap failure is dominated by hydrostatic stresses and is a ductile failure in which pore collapse occurs in the form of distributed microcracking [120,121]. Accordingly, the uniaxial compressive strength, eq. (A-12) can be obtained by solving eq. (A-11):

$$
\begin{gathered}
\frac{\sigma_{y c}}{\sqrt{3}}=A_{1} \sigma_{y c}{ }^{2}+\sigma_{y c} \tan \phi+C \\
\sigma_{y c}=-\frac{3 \tan \phi-\sqrt{3}+3 \sqrt{(\tan \phi)^{2}-(2 / 3) \sqrt{3} \tan \phi-4 A_{1} C+(1 / 3)}}{6 A_{1}}
\end{gathered}
$$

The uniaxial tensile strength $\left(\sigma_{y t}[\mathrm{~Pa}]\right)$ at the tension cut-off $[36,122]$ can be determined according to Griffith's failure envelope $[123,124]$ :

$$
\sigma_{y t}=\frac{c}{2}
$$

Therefore the hydrostatic tensile strength $[36,122]$ is: 
Accepted version. Paper published as: Ghourchian et al., On the mechanism of plastic shrinkage cracking in fresh cementitious materials. Cem Concr Res (2019) 115: 251-263

https://doi.org/10.1016/j.cemconres.2018.10.015

$$
p_{p e l-t}=\frac{\sigma_{y t}}{3}=\frac{c}{6}
$$

\section{References}

[1] P. Morris, P. Dux, Cracking of plastic concrete, Aust. J. Civ. Eng. 1 (2003) 17-21.

[2] S.P. Shah, W.J. Weiss, W. Yang, Shrinkage Cracking--Can It Be Prevented?, Concr. Int. 20 (1998) 51-55.

[3] W.J. Weiss, W. Yang, S.P. Shah, Factors influencing durability and early-age cracking in highstrength concrete structures, Spec. Publ. 189 (2000) 387-410.

[4] C.A. Menzel, Causes and prevention of crack development in plastic concrete, Proc. Portland Cem. Assoc. (1954) 130-136.

[5] W. Lerch, Plastic shrinkage, in: ACl 52nd Annu. Conv., Journal of the American Concrete Institute, Philadelphia, 1957: pp. 797-802.

[6] T.C. Powers, Properties of Fresh Concrete, John Wiley and Sons, Inc N. Y. (1968) 301.

[7] N. Banthia, R. Gupta, Plastic shrinkage cracking in cementitious repairs and overlays, Mater. Struct. 42 (2009) 567-579.

[8] A.A. Almussalam, M. Maslehuddin, M. Abdul-Waris, F.H. Dakhil, O.S.B. Al-Amoudi, Plastic shrinkage cracking of blended cement concretes in hot environments, Mag. Concr. Res. 51 (1999) 241-246.

[9] T.A. Hammer, Deformations, strain capacity and cracking of concrete in plastic and early hardening phases, NTNU, 2007.

[10] T.S. Tan, T.H. Wee, S.A. Tan, C.T. Tam, S.L. Lee, A consolidation model for bleeding of cement paste, Adv. Cem. Res. 1 (1987) 18-26.

[11] P.J. Uno, Plastic shrinkage cracking and evaporation formulas, ACI Mater. J. 95 (1998) 365-375.

[12] A. Radocea, A model of plastic shrinkage, Mag. Concr. Res. 46 (1994) 125-132.

[13] M.D. Cohen, J. Olek, W.L. Dolch, Mechanism of plastic shrinkage cracking in portland cement and portland cement-silica fume paste and mortar, Cem. Concr. Res. 20 (1990) 103-119.

[14] H.-G. Kwak, S. Ha, W.J. Weiss, Experimental and numerical quantification of plastic settlement in fresh cementitious systems, J. Mater. Civ. Eng. 22 (2010) 951-966.

[15] S. Ghourchian, M. Wyrzykowski, P. Lura, A poromechanics model for plastic shrinkage of fresh cementitious materials, Cem. Concr. Res. 109 (2018) 120-132.

[16] V. Slowik, T. Hübner, M. Schmidt, B. Villmann, Simulation of capillary shrinkage cracking in cement-like materials, Cem. Concr. Compos. 31 (2009) 461-469.

[17] V. Slowik, J.W. Ju, Discrete modeling of plastic cement paste subjected to drying, Cem. Concr. Compos. 33 (2011) 925-935.

[18] W.-F. Chen, Plasticity in reinforced concrete, J. Ross Publishing, 2007.

[19] P. Beverly, Fib Model Code for Concrete Structures 2010, Ernst \& Sohn, 2013.

[20] S. Mohammadi, Extended finite element method: for fracture analysis of structures, John Wiley \& Sons, 2008.

[21] D.P. Bentz, E.J. Garboczi, Y. Lu, N. Martys, A.R. Sakulich, W.J. Weiss, Modeling of the influence of transverse cracking on chloride penetration into concrete, Cem. Concr. Compos. 38 (2013) 65-74. 
Accepted version. Paper published as: Ghourchian et al., On the mechanism of plastic shrinkage cracking in fresh cementitious materials. Cem Concr Res (2019) 115: 251-263

https://doi.org/10.1016/j.cemconres.2018.10.015

[22] A. Akhavan, F. Rajabipour, Evaluating ion diffusivity of cracked cement paste using electrical impedance spectroscopy, Mater. Struct. (2013) 1-12.

[23] M. Pour-Ghaz, F. Rajabipour, J. Couch, J. Weiss, Modeling fluid transport in cementitious systems with crack-like (notch) geometries, in: Proc. 2nd Int. RILEM Workshop Concr. Durab. Serv. Life Plan. Haifa Isr., 2009.

[24] V. Picandet, A. Khelidj, H. Bellegou, Crack effects on gas and water permeability of concretes, Cem. Concr. Res. 39 (2009) 537-547.

[25] F. Ghasemzadeh, M. Pour-Ghaz, Effect of damage on moisture transport in concrete, J. Mater. Civ. Eng. 27 (2014) 04014242.

[26] R. Combrinck, W.P. Boshoff, Fundamentals of plastic settlement cracking in concrete, in: Constr. Mater. Struct. Proc. First Int. Conf. Constr. Mater. Struct., IOS Press, 2014: p. 354.

[27] ASTM C1579-13, Standard Test Method for Evaluating Plastic Shrinkage Cracking of Restrained Fiber Reinforced Concrete (Using a Steel Form Insert), ASTM International, West Conshohocken, PA, 2013, www.astm.org, (n.d.).

[28] D. Ravina, R. Shalon, Plastic shrinkage cracking, in: ACl J. Proc., ACl, 1968.

[29] A. Sivakumar, M. Santhanam, A quantitative study on the plastic shrinkage cracking in high strength hybrid fibre reinforced concrete, Cem. Concr. Compos. 29 (2007) 575-581.

[30] D.H. Nguyen, V.T. Dao, P. Lura, Tensile properties of concrete at very early ages, Constr. Build. Mater. 134 (2017) 563-573.

[31] L. Laloui, C. Cekerevac, Thermo-plasticity of clays: an isotropic yield mechanism, Comput. Geotech. 30 (2003) 649-660.

[32] A. Casagrande, The determination of the pre-consolidation load and its practical significance, in: Proc. Int. Conf. Soil Mech. Found. Eng., Harvard University Cambridge, 1936: pp. 60-64.

[33] A.B. Comsol, Geomechanics module user's guide, Comsol AB, Stockholm, 2012.

[34] B. Bresler, K.S. Pister, Strength of concrete under combined stresses, in: J. Proc., 1958: pp. 321345.

[35] K. Raoufi, J. Schlitter, D. Bentz, J. Weiss, Parametric assessment of stress development and cracking in internally cured restrained mortars experiencing autogenous deformations and thermal loading, Adv. Civ. Eng. 2011 (2011).

[36] K.J. Bathe, M. Kojic, Inelastic analysis of solids and structures, Springer, 2005.

[37] D.C. Drucker, W. Prager, Soil mechanics and plastic analysis or limit design, Q. Appl. Math. 10 (1952) 157-165.

[38] P. Lura, B. Pease, G.B. Mazzotta, F. Rajabipour, J. Weiss, Influence of shrinkage-reducing admixtures on development of plastic shrinkage cracks, ACI Mater. J. 104 (2007).

[39] A. Leemann, P. Nygaard, P. Lura, Impact of admixtures on the plastic shrinkage cracking of selfcompacting concrete, Cem. Concr. Compos. 46 (2014) 1-7.

[40] P. Fontana, S. Pirskawetz, P. Lura, Plastic shrinkage cracking risk of concrete-Evaluation of test methods, in: 7th RILEM Int. Conf. Crack. Pavements, Springer, 2012: pp. 591-600.

[41] M. Norfleet, A model to quantify the influence of fiber reinforcement on plastic shrinkage cracking, Purdue University, 2008.

[42] A. Sivakumar, Studies on influence of water-cement ratio on the early age shrinkage cracking of concrete systems, J. Civ. Eng. Constr. Technol. 4 (2013).

[43] T. Rahmani, B. Kiani, M. Bakhshi, M. Shekarchizadeh, Application of different fibers to reduce plastic shrinkage cracking of concrete, in: 7th RILEM Int. Conf. Crack. Pavements, Springer, 2012: pp. 635-642. 
Accepted version. Paper published as: Ghourchian et al., On the mechanism of plastic shrinkage cracking in fresh cementitious materials. Cem Concr Res (2019) 115: 251-263

https://doi.org/10.1016/j.cemconres.2018.10.015

[44] C. Qi, J. Weiss, J. Olek, Characterization of plastic shrinkage cracking in fiber reinforced concrete using image analysis and a modified Weibull function, Mater. Struct. 36 (2003) 386-395.

[45] S. Ranjbar, Effect of pre-wetted perlite and fibers on autogenous and plastic shrinkage of high strength concrete, University of British Columbia, n.d.

[46] R. Combrinck, W.P. Boshoff, Typical plastic shrinkage cracking behaviour of concrete, Mag. Concr. Res. 65 (2013) 486-493.

[47] A. Hossain, S. Shrestha, J. Summers, Properties of concrete incorporating ultrafine fly ash and silica fume, Transp. Res. Rec. J. Transp. Res. Board. (2009) 41-46.

[48] A. Hossain, S. Shirazi, J. Persun, N. Neithalath, Properties of concrete containing vitreous calcium aluminosilicate pozzolan, Transp. Res. Rec. J. Transp. Res. Board. (2008) 32-38.

[49] R. Henkensiefken, P. Briatka, D. Bentz, T. Nantung, J. Weiss, Plastic shrinkage cracking in internally cured mixtures made with pre-wetted lightweight aggregate, Concr. Int. 32 (2010) 4954.

[50] K. Yang, M. Zhong, B. Magee, C. Yang, C. Wang, X. Zhu, Z. Zhang, Investigation of effects of Portland cement fineness and alkali content on concrete plastic shrinkage cracking, Constr. Build. Mater. 144 (2017) 279-290.

[51] P. Soroushian, F. Mirza, A. Alhozajiny, Plastic shrinkage cracking of polypropylene fiber reinforced concrete, Mater. J. 92 (1993) 553-560.

[52] N.S. Berke, M.P. Dallaire, Effect of low addition rates of polypropylene fibers on plastic shrinkage cracking and mechanical properties of concrete, Spec. Publ. 142 (1994) 19-42.

[53] A. Sivakumar, M. Santhanam, Experimental methodology to study plastic shrinkage cracks in high strength concrete, Meas. Monit. Model. Concr. Prop. (2006) 291-296.

[54] Y. Shao, A. Mirmiran, Control of plastic shrinkage cracking of concrete with carbon fiberreinforced polymer grids, J. Mater. Civ. Eng. 19 (2007) 441-444.

[55] J. Mora-Ruacho, R. Gettu, A. Aguado, Influence of shrinkage-reducing admixtures on the reduction of plastic shrinkage cracking in concrete, Cem. Concr. Res. 39 (2009) 141-146.

[56] W.P. Boshoff, R. Combrinck, Modelling the severity of plastic shrinkage cracking in concrete, Cem. Concr. Res. 48 (2013) 34-39.

[57] I. Löfgren, O. Esping, Early age cracking of self-compacting concrete, in: Int. RILEM Conf. Vol. Chang. Hardening Concr. Test. Mitigation" Lyngby, 2006: pp. 251-260.

[58] C.L. Hwang, C.T. Chen, L.A.T. Bui, F.R. Kurniawan, The Study on the Early Age Cracking due to the Addition of Silica Fume into Concrete and the Trouble-Shooting Strategy, in: Adv. Mater. Res., Trans Tech Publ, 2011: pp. 824-829.

[59] J. Branch, D.J. Hannant, M. Mulheron, Factors affecting the plastic shrinkage cracking of highstrength concrete, Mag. Concr. Res. 54 (2002) 347-354.

[60] O. Esping, Effect of limestone filler BET ( 2 O)-area on the fresh and hardened properties of selfcompacting concrete, Cem. Concr. Res. 38 (2008) 938-944.

[61] F. Sayahi, M. Emborg, H. Hedlund, I. Löfgren, PLASTIC SHRINKAGE CRACKING IN SELFCOMPACTING CONCRETE: A PARAMETRIC STUDY, in: MSSCE2016 RILEM 22082016, Rilem publications, 2016: pp. 609-619.

[62] R.D. Toledo Filho, M.A. Sanjuan, Effect of low modulus sisal and polypropylene fibre on the free and restrained shrinkage of mortars at early age, Cem. Concr. Res. 29 (1999) 1597-1604.

[63] P.N. Balaguru, S.P. Shah, Fiber-reinforced cement composites, 1992.

[64] NORDTEST NT BUILD 433, Concrete: Cracking Tendency - Exposure to Drying During the First 24 Hours, (1995). 
Accepted version. Paper published as: Ghourchian et al., On the mechanism of plastic shrinkage cracking in fresh cementitious materials. Cem Concr Res (2019) 115: 251-263

https://doi.org/10.1016/j.cemconres.2018.10.015

[65] Y. Liu, The Influence of Fly Ash on the Crack Performance of Airport Pavement Concrete by Dumbbell Test Method, in: Adv. Mater. Res., Trans Tech Publ, 2013: pp. 1719-1722.

[66] S.-T. Lin, R. Huang, T.-L. Weng, Effect of Water Soluble Polymer and Fiber on the Early-Age Shrinkage Cracking of Cementitious Composites, J. Mar. Sci. Technol. 20 (2012) 295-303.

[67] S.-T. Lin, R. Huang, Effect of viscosity modifying agent on plastic shrinkage cracking of cementitious composites, Mater. Struct. 43 (2010) 651-664.

[68] S.-T. Lin, R. Huang, T.-L. Weng, Effect of mineral admixtures and viscosity modifying admixtures on plastic shrinkage cracking of cementitious composites, J. Chin. Inst. Eng. 34 (2011) 287-297.

[69] H.R. Shen, Y.X. She, P.W. Gao, The influence of polypropylene fiber on the performance of concrete pavement, in: Appl. Mech. Mater., Trans Tech Publ, 2012: pp. 1099-1103.

[70] L. Ruiz-Ripoll, B.E. Barragán, S. Moro, J. Turmo, Digital imaging methodology for measuring early shrinkage cracking in concrete, Strain. 49 (2013) 267-275.

[71] N. Banthia, C. Yan, S. Mindess, Restrained shrinkage cracking in fiber reinforced concrete: a novel test technique, Cem. Concr. Res. 26 (1996) 9-14.

[72] N. Banthia, R. Gupta, Influence of polypropylene fiber geometry on plastic shrinkage cracking in concrete, Cem. Concr. Res. 36 (2006) 1263-1267.

[73] N. Banthia, R. Gupta, TEST METHOD FOR EVALUATION OF PLASTIC SHRINKAGE CRACKING IN FIBER-REINFORCED CEMENTITIOUS MATERIALS, Exp. Tech. 31 (2007) 44-48.

[74] P. Ghoddousi, A.A.S. Javid, Plastic Shrinkage Evaluation of Self-Consolidating Concrete as Repair Materials Based on Restrained and Free Strain Measurements, in: Des. Prod. Place. Self-Consol. Concr., Springer, 2010: pp. 295-306.

[75] R. Malathy, K. Subramanian, M. Rameshkumar, Effect of glass fibers on restrained plastic shrinkage cracking of HPC with silica fume, (2007).

[76] S.R.R. Senthilkumar, S.C. Natesan, Prediction of restrained plastic shrinkage cracking in plain cement concrete, Mag. Concr. Res. 57 (2005) 579-587.

[77] B. Nabil, A. Aissa, B.I. Aguida, Effectiveness of Different Solutions to Reduce Plastic Shrinkage in Hot Climate Concreting, in: Vol. Two Three Second Int. Conf. Sustain. Constr. Mater. Technol. June, 2010.

[78] S.J. Li, H.P. Qian, Crack Resistance and Permeability of Hybrid Fiber Reinforced Concrete Application in Understructure Work, in: Appl. Mech. Mater., Trans Tech Publ, 2013: pp. 257-261.

[79] GB/T 50082-2009 (National Standard of the People's Republic of China):The Test Method of Longterm and Durability on Ordinary Concrete, China Architecture and Building Press, 2009.

[80] P.P. Kraai, A proposed test to determine the cracking potential due to drying shrinkage of concrete, Concr. Constr. 30 (1985) 775-778.

[81] C.A. Shaeles, K.C. Hover, Influence of mix proportions and construction operations on plastic shrinkage cracking in thin slabs, Mater. J. 85 (1988) 495-504.

[82] Ö. Eren, K. Marar, Effect of steel fibers on plastic shrinkage cracking of normal and high strength concretes, Mater. Res. 13 (2010) 135-141.

[83] V. Ramakrishnan, R. Zellers, A.K. Patnaik, Plastic shrinkage reduction potential of a new high tenacity monofilament polypropylene fiber, Spec. Publ. 243 (2007) 49-62.

[84] K. Gunasekaran, R. Annadurai, P.S. Kumar, Plastic shrinkage and deflection characteristics of coconut shell concrete slab, Constr. Build. Mater. 43 (2013) 203-207.

[85] F. Pelisser, A.B. da S.S. Neto, H.L. La Rovere, R.C. de Andrade Pinto, Effect of the addition of synthetic fibers to concrete thin slabs on plastic shrinkage cracking, Constr. Build. Mater. 24 (2010) 2171-2176. 
Accepted version. Paper published as: Ghourchian et al., On the mechanism of plastic shrinkage cracking in fresh cementitious materials. Cem Concr Res (2019) 115: 251-263

https://doi.org/10.1016/j.cemconres.2018.10.015

[86] N.F. Medina, G. Barluenga, F. Hernández-Olivares, Enhancement of durability of concrete composites containing natural pozzolans blended cement through the use of Polypropylene fibers, Compos. Part B Eng. 61 (2014) 214-221.

[87] A. Hosoda, PLASTIC SHRINKAGE CRACK CONTROLLING MECHANISM OF SYNTHETIC SHORT FIBER, in: 30th Conference on Our World in Concrete and Structures (OWICs), Singapore, 2005. http://cipremier.com/100030033.

[88] A.M. Alhozaimy, A.I. Al-Negheimish, Plastic Shrinkage in Hot and Arid Environments, Concr. Int. 31 (2009) 26-32.

[89] S. Ghourchian, M. Wyrzykowski, P. Lura, The bleeding test: A simple method for obtaining the permeability and bulk modulus of fresh concrete, Cem. Concr. Res. 89 (2016) 249-256.

[90] A. Verruijt, An Introduction to Soil Mechanics, Springer International Publishing, 2018.

[91] E.E. Alonso, A. Gens, A. Josa, Constitutive model for partially saturated soils, Géotechnique. 40 (1990) 405-430.

[92] M. Umar, A. Sadrekarimi, Accuracy of determining pre-consolidation pressure from laboratory tests, Can. Geotech. J. (2016).

[93] K. Terzaghi, Theoretical soil mechanics, Chapman And Hali, Limited John Wiler And Sons, Inc; New York, 1944.

[94] A. Verruijt, Computational geomechanics, Springer Science \& Business Media, 1995.

[95] Y. Fung, Foundations of solid mechanics, Prentice Hall, 1965.

[96] D.G. Fredlund, H. Rahardjo, M.D. Fredlund, Unsaturated soil mechanics in engineering practice, John Wiley \& Sons, 2012.

[97] J.A. De Wet, Three-Dimensional Consolidation, Highw. Res. Board Bull. (1962).

[98] L.E. Bowles, Foundation analysis and design, McGraw-hill, 1996.

[99] M. Wyrzykowski, P. Lura, Moisture dependence of thermal expansion in cement-based materials at early ages, Cem. Concr. Res. 53 (2013) 25-35.

[100] W.-F. Chen, E. Mizuno, Nonlinear analysis in soil mechanics, Elsevier Amsterdam, 1990.

[101] G. Lu, K. Wang, Theoretical and experimental study on shear behavior of fresh mortar, Cem. Concr. Compos. 33 (2011) 319-327.

[102] E. Bauer, E. Fonseca da Silva, J.G. Gomes De Sousa, M.C. de Freitas Salomão, Friction influence between particles in the behavior of flow of lime-rendering mortars, J. Mater. Civ. Eng. 27 (2014) 04014136.

[103] A. Alexandridis, N.J. Gardner, Mechanical behaviour of fresh concrete, Cem. Concr. Res. 11 (1981) 323-339.

[104] J.A. Collins, Failure of materials in mechanical design: analysis, prediction, prevention, John Wiley \& Sons, 1993.

[105] S. Ghourchian, M. Wyrzykowski, P. Lura, A practical approach for reducing the risk of plastic shrinkage cracking of concrete, RILEM Tech. Lett. 2 (2017) 40-44.

[106] E. Haghighi, E. Shahraeeni, P. Lehmann, D. Or, Evaporation rates across a convective air boundary layer are dominated by diffusion, Water Resour. Res. 49 (2013) 1602-1610.

[107] S. Ghourchian, M. Wyrzykowski, L. Baquerizo, P. Lura, Susceptibility of Portland cement and blended cement concretes to plastic shrinkage cracking, Cem. Concr. Compos. 85 (2018) 44-55.

[108] EN 12350-7, Testing fresh concrete. Air content. Pressure methods, (2009).

[109] EN 1015-3: Methods of test for mortar for masonry. Determination of consistence of fresh mortar (by flow table), (n.d.).

[110] F. d'Onza, A. d'Onofrio, C. Mancuso, Effects of Unsturated Soil State on the Local Seismic Response of Soil Deposits, in: Proc. 1st Eur. Conf. Unsaturated Soils, Durham, 2008: pp. 531-536. 
Accepted version. Paper published as: Ghourchian et al., On the mechanism of plastic shrinkage cracking in fresh cementitious materials. Cem Concr Res (2019) 115: 251-263

https://doi.org/10.1016/j.cemconres.2018.10.015

[111] S.H. Ebrahimi, S. Mohammadi, A. Asadpoure, An extended finite element (XFEM) approach for crack analysis in composite media, Int J Civ Eng. 6 (2008) 198-207.

[112] T. Cajuhi, L. Sanavia, L. De Lorenzis, Phase-field modeling of fracture in variably saturated porous media, Comput. Mech. (2017) 1-20.

[113] P. Lura, C. Di Bella, Trindler, Walter, Münch, Beat, Leemann, Andreas, An advanced experimental setup to study plastic shrinkage cracking of concrete., in: Dubai, United Arab Emirates, 2011.

[114] F.M. Capaldi, Continuum mechanics: constitutive modeling of structural and biological materials, Cambridge University Press, 2012.

[115] V. Slowik, M. Schmidt, Early age cracking and capillary pressure controlled concrete curing, Adv. Cem.-Based Mater. (2010).

[116] A.S. Khan, S. Huang, Continuum theory of plasticity, John Wiley \& Sons, 1995.

[117] Z.P. Bažant, Y. Xiang, Size effect in compression fracture: splitting crack band propagation, J. Eng. Mech. 123 (1997) 162-172.

[118] R.M. Jones, Deformation theory of plasticity, Bull Ridge Corporation, 2009.

[119] J.F. Georgin, J.M. Reynouard, Modeling of structures subjected to impact: concrete behaviour under high strain rate, Cem. Concr. Compos. 25 (2003) 131-143.

[120] R. Ulusay, Ö. Aydan, H. Gerçek, M.A. Hindistan, E. Tuncay, Rock Mechanics and Rock Engineering: From the Past to the Future, Taylor \& Francis Group, 2016.

[121] D. Sfer, I. Carol, R. Gettu, G. Etse, Study of the behavior of concrete under triaxial compression, J. Eng. Mech. 128 (2002) 156-163.

[122] I.S. Sandler, F.L. Dimaggio, G.Y. Baladi, Generalized cap model for geological materials, J. Geotech. Geoenvironmental Eng. 102 (1976).

[123] V.T. Dao, P.F. Dux, P.H. Morris, Tensile properties of early-age concrete, ACI Mater. J. 106 (2009).

[124] W.F. Brace, An extension of the Griffith theory of fracture to rocks, J. Geophys. Res. 65 (1960) 3477-3480. 